\title{
Protein phosphatase-1 regulates Akt1 signal transduction pathway to control gene expression, cell survival and differentiation
}

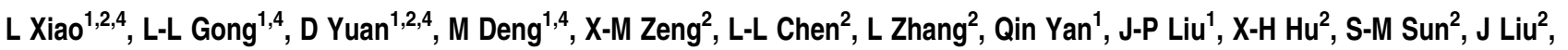

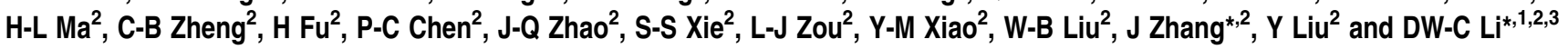

\begin{abstract}
AKT pathway has a critical role in mediating signaling transductions for cell proliferation, differentiation and survival. Previous studies have shown that AKT activation is achieved through a series of phosphorylation steps: first, AKT is phosphorylated at Thr-450 by JNK kinases to prime its activation; then, phosphoinositide-dependent kinase 1 phosphorylates AKT at Thr-308 to expose the Ser-473 residue; and finally, AKT is phosphorylated at Ser-473 by several kinases (PKD2 and others) to achieve its full activation. For its inactivation, the PH-domain containing phosphatases dephosphorylate AKT at Ser-473, and protein serine/threonine phosphatase-2A (PP-2A) dephosphorylates it at Thr-308. However, it remains unknown regarding which phosphatase dephosphorylates AKT at Thr-450 during its inactivation. In this study, we present both in vitro and in vivo evidence to show that protein serine/threonine phosphatase-1 (PP-1) is a major phosphatase that directly dephosphorylates AKT to modulate its activation. First, purified PP-1 directly dephosphorylates AKT in vitro. Second, immunoprecipitation and immunocolocalization showed that PP-1 interacts with AKT. Third, stable knock down of PP- $1 \alpha$ or PP- $1 \beta$ but not PP- $1 \gamma$, PP-2A $\alpha$ or PP-2A $\beta$ by shRNA leads to enhanced phosphorylation of AKT at Thr-450. Finally, overexpression of PP- $1 \alpha$ or PP-1 $\beta$ but not PP- $1 \gamma$, PP-2A $\alpha$ or PP-2A $\beta$ results in attenuated phosphorylation of AKT at Thr-450. Moreover, our results also show that dephosphorylation of AKT by PP-1 significantly modulates its functions in regulating the expression of downstream genes, promoting cell survival and modulating differentiation. These results show that PP-1 acts as a major phosphatase to dephosphorylate AKT at Thr-450 and thus modulate its functions.
\end{abstract}

Cell Death and Differentiation (2010) 17, 1448-1462; doi:10.1038/cdd.2010.16; published online 26 February 2010

Protein dephosphorylation at the serine and threonine residues of various proteins, similar to their cognate phosphorylation, has important roles in regulating various cellular processes, such as cell differentiation and apoptosis. ${ }^{1,2}$ In eukaryotes, $\sim 98 \%$ of dephosphorylation occurs at the serine/threonine residues and two major protein phosphatases, namely phosphatase-1 (PP-1) and phosphatase-2A (PP-2A $)^{3,4}$ contribute $>90 \%$ of serine/threonine phosphatase activity. In this regard, we have recently shown that both PP-1 and PP-2A have important roles in modulating apoptosis. ${ }^{5,6}$ $\mathrm{PP}-1$ promotes survival through its negative regulation of $\mathrm{p53}$, which is a master regulator of apoptosis. It directly dephosphorylates p53 at Ser-15 and Ser-37 to attenuate its transcriptional and apoptotic activities. ${ }^{5} \mathrm{PP}-2 \mathrm{~A}$ is also found to modulate the phosphorylation status of p53 at these sites to suppress stress-induced apoptosis. ${ }^{6,7}$ In this study, we present the first evidence to show that PP-1 has a critical role during the activation process of Akt1 signaling pathway.
The Akt/protein kinase B consists of three family members (Akt1, Akt2 and Akt3) and has an important role in regulating the survival of most cells. ${ }^{8,9}$ It does so through regulation of the functions of various transcription factors that control both proapoptotic and antiapoptotic genes. ${ }^{9,10}$ Examples of such genes include the those encoding IKK $\beta$, BAD and GSK. ${ }^{8,9}$ Deregulation of the Akt signaling pathway leads to the formation of cancer. ${ }^{11-14}$

In response to growth factors and various stimuli, Akt becomes activated through a series of phosphorylation events. Among the three members, activation of Akt 1 is well studied. ${ }^{8,14}$ First, a recent study has shown that Akt1 is primed through phosphorylation at Thr-450 in the cytosol by the stress-activated protein kinase, JNK1/2, under certain conditions. ${ }^{15,16}$ Second, after activation by the ligand-regulated receptor-tyrosine kinases, the phosphoinositide-3 kinase (PI3K) generates phosphoinositol-3,4,5-triphosphate (PIP3), the lipid secondary messenger that recruits phosphoinositide-

\footnotetext{
${ }^{1}$ Department of Biochemistry and Molecular Biology, University of Nebraska Medical Center, Omaha, Nebraska 68198-5870, USA; ${ }^{2}$ Key Laboratory of Protein Chemistry and Developmental Biology of Educational Ministry of China, College of Life Sciences, Hunan Normal University, Changsha, Hunan 410081, China and ${ }^{3}$ Department of Ophthalmology and Visual Sciences, University of Nebraska Medical Center, Omaha, Nebraska 68198-5540, USA

*Corresponding authors: DW-C Li, Department of Biochemistry and Molecular Biology, University of Nebraska Medical Center, 668 S 41th Street, Omaha, Nebraska 68198-5870, USA. Tel: + 402559 5073; Fax: + 402559 6650; E-mail: dwli1688@ hotmail.com or J Zhang, College of Life Sciences, Hunen Normal University, Changsha, Hunen 410081, China. Tel: + 07318887 2792; Fax: + 07318887 2792; E-mail: zhangijan @ hunnu.edu.cn

${ }^{4}$ These authors contributed equally to this work.

Keywords: PP-1; dephosphorylation; Akt1; apoptosis; differentiation

Abbreviations: ARPE-19, retinal pigmental epithelial cells; bFGF, basic fibroblast growth factor; CA, Calyculin A; HLE or HLECs, human lens epithelial cells; JNK1/2/3, c-Jun terminal kinase 1/2/3; PKD1/2, phosphoinositide-dependent kinase 1/2; PHLPPs, PH-domain phosphatases; PIP3, phosphoinositol-3,4,5-triphosphate; PP-1, protein serine/threonine phosphatase-1; PP-2A, protein serine/threonine phosphatase-2A; OA, okadaic acid; S or Ser, serine residue; $T$ or Thr, threonine residue Received 04.11.09; revised 21.12.09; accepted 25.1.10; Edited by H Ichijo; published online 26.2.10
} 
dependent kinase 1 (PDK1) and Akt1 to the membrane through its $\mathrm{PH}$ domain. ${ }^{8,9}$ PDK1 thus phosphorylates Akt1 at Thr-308, causing a confirmation change of Akt1 to expose its C-terminal hydrophobic motif. ${ }^{17,18}$ Finally, after the configuration change, Akt1 may either undergo autophosphorylation at Ser-473, ${ }^{19,20}$ or become phosphorylated by a second kinase referred to as $P D K 2^{21}$ or other kinases ${ }^{22,23}$ at Ser-473 to achieve its full activation.

Akt signaling is terminated by the lipid phosphatase PTEN through dephosphorylation of PIP3. ${ }^{24,25}$ The later event leads to dephosphorylation of Akt 1 by the $\mathrm{PH}$-domain phosphatases (PHLPPs) at Ser-473. ${ }^{26,27}$ Dephosphorylation of Akt1 at Thr-308 is mediated by PP-2A. ${ }^{28,29}$ On the other hand, dephosphorylation of Akt1 at Thr-450 remains unknown. In this study, we present both in vitro and in vivo evidence to show that PP-1 is a major phosphatase dephosphorylating Akt1 at Thr-450. Through this action, PP-1 thus modulates AKT signaling pathway functions in regulating gene expression, cell survival and differentiation.

\section{Results}

Inhibition of PP-1 but not PP-2A induces hyperphosphorylation of Akt1 at Thr-450. Recent studies have shown that JNK $1 / 2$ are involved in priming Akt1 by phosphorylating Thr-450 for further activation by PDK1 and other kinases during hypoxia/reoxygenationinduced injury of cardiomyocytes under both in vitro and in vivo conditions. ${ }^{15,16}$ To confirm that JNKs also phosphorylate AKT1 at Thr-450, we treated human lens epithelial cells (HLECs) with $1 \mu \mathrm{M}$ of SP600125 to inhibit JNK-1, JNK-2 and JNK-3. ${ }^{30}$ As shown in Supplementary Figure 1A, after inhibition of JNKs for $48 \mathrm{~h}$, the basic phosphorylation of AKT1 at Thr-450 was significantly decreased. Next, to explore which phosphatases may dephosphorylate Akt1 at Thr-450, we treated HLECs with okadaic acid (OA) at 0, 10 and $200 \mathrm{nM}$ to inhibit either PP-2A (10 nM) or PP-1 (200 nM). $\mathrm{PP}-2 \mathrm{~A}$ is 100 times more sensitive to OA than PP-1 because of the unique structure of the catalytic subunit. ${ }^{31}$ At these OA concentrations, the activities of JNKs showed little changes (Supplementary Figure 1B). On the other hand, although the inhibition of PP-2A by $10 \mathrm{nM}$ OA did not lead to significant change on Akt phosphorylation at Thr-450, inhibition of PP-1 by $200 \mathrm{nM}$ OA led to more than two-fold increases in Akt phosphorylation at Thr-450 (bottom diagram of Figure 1a) The enhanced phosphorylation induced by $200 \mathrm{nM}$ OA is not derived from changed JNK activity as pretreatment of HLE with $1 \mu \mathrm{M}$ SP600125 did not show significant effect on Akt phosphorylation at Thr-450 (Figure 1b). Similar results were also obtained from another cell line, the human retina pigment epithelial cells (ARPE-19) (Figure 1c and d). To further confirm that inhibition of PP-1 but not PP-2A causes hyperphosphorylation of Akt1 at Thr-450, we treated the two types of cells with calyculin $A$, which has the same $I_{50}$ to both PP-1 and PP-2A. As shown in Supplementary Figure 2, calyculin A treatment led to dose-dependent hyperphosphorylation of Akt1 at Thr-450 in both types of cells. These results suggest that PP-1 but not PP-2A seems to be the major phosphatase responsible for dephosphorylation of Akt1 at Thr-450.
PP-1 can dephosphorylate Akt1 at Thr-450 in vitro. To show that PP-1 is the major phosphatase that could dephosphorylate Akt at Thr-450, we conducted in vitro dephosphorylation assays using purified PP-1 (obtained from New England Biolabs, Ipswich, MA, USA) and PP-2A (from Calbiochem, Gibbstown, NJ, USA). To prepare the dephosphorylation substrates, the GST full-length Akt1 protein and its mutant form (Akt1-T450A) were prepared (Figure 2a), further purified by GST columns (Figure $2 \mathrm{~b}$ ) and then cleaved with thrombin to yield purified Akt1 and Akt1-T450A proteins without GST, which were labeled with JNK $1 / 2$ in the presence of ${ }^{32} \mathrm{P}-\gamma$-ATP. The labeled proteins were used as substrates for the in vitro dephosphorylation assays by purified PP-1 and PP-2A. After dephosphorylation, the free ${ }^{32} \mathrm{P}$ released from substrate proteins by $\mathrm{PP}-1$ or $\mathrm{PP}-2 \mathrm{~A}$ was measured in a scintillation counter. As shown in Figure 2c, in vitro enzyme concentration-dependent assays showed that PP-1 was more efficient than PP-2A in dephosphorylating the labeled substrate with the same amount of enzyme (PP-1 and PP-2A activities were calibrated as described previously ${ }^{5,6}$ ). Similarly, time-dependent assays with 1 Unit of PP-1 or PP-2A showed that the free ${ }^{32} \mathrm{P}$ released by $\mathrm{PP}-1$ was much more prominent than PP-2A (Figure 2d). Dephosphorylation of the labeled mutant Akt1-T450A by PP-1 or PP-2A produced just background levels of free ${ }^{32} \mathrm{P}$ (Figure $2 \mathrm{c}$ and $\mathrm{d}$ ). Together, these results suggest that although both $\mathrm{PP}-1$ and $\mathrm{PP}-2 \mathrm{~A}$ can dephosphorylate Akt1 at Thr-450 in vitro, PP-1 is a more efficient phosphatase to dephosphorylate Akt1 at Thr-450.

The catalytic subunits of PP-1 form a complex with Akt1. To show that PP-1 dephosphorylates Akt1 at Thr-450 under physiological conditions, we first examined whether the catalytic subunit for PP-1 could form an interacting complex with Akt1. To do so, total proteins extracted from HLECs were subjected to coimmunoprecipitation assays. When the proteins coimmunoprecipitated (Co-IP) by goat anti-PP $-1 \alpha / \beta$ were probed with either the antibody against Akt 1 or $\mathrm{PP}-1 \alpha / \beta$ isoforms of the catalytic subunits, it was found that a clear band of Akt1 was brought down by anti-PP-1 $\alpha / \beta$ (Figure 3a). In the reverse Co-IP assay, it was also found that a clear band of PP- $1 \alpha / \beta$ was bound to Akt1 (Figure 3a). Thus, PP-1 and Akt1 form a strong interacting complex in HLECs. Similar results were obtained using ARPE-19 cells (Figure 3b). Together, immunoprecipitation assays confirmed that in both HLECs and ARPE-19, PP-1 and Akt1 can form an interacting complex. Our results also showed that PP-2A interacts with Akt1 (data not shown). This is not surprising as previous studies have shown that PP-2A dephosphorylates Akt1 at Thr-308. ${ }^{28,29}$ Immunocytochemistry analysis showed that both PP-1 and Akt1 displayed partial overlapping in both the cytoplasm and the nucleus within the HLECs (Figure $3 c-f$ ) and ARPE-19 cells (Figure $3 g-j$ ). In summary, our results showed that PP-1 can dephosphorylate Akt1 at Thr-450.

Knockdown of PP-1 $\alpha / \beta$ but not PP-1 $\gamma$ or PP-2A $\alpha / \beta$ leads to significant hyperphosphorylation of Akt1 at Thr-450.

To confirm that PP-1 is the major phosphatase dephosphorylating Akt1 at Thr-450 under physiological conditions, we established stable clones to knock down each of the 3 PP -1 catalytic subunits $(\alpha, \beta$ and $\gamma)$ and two 
a
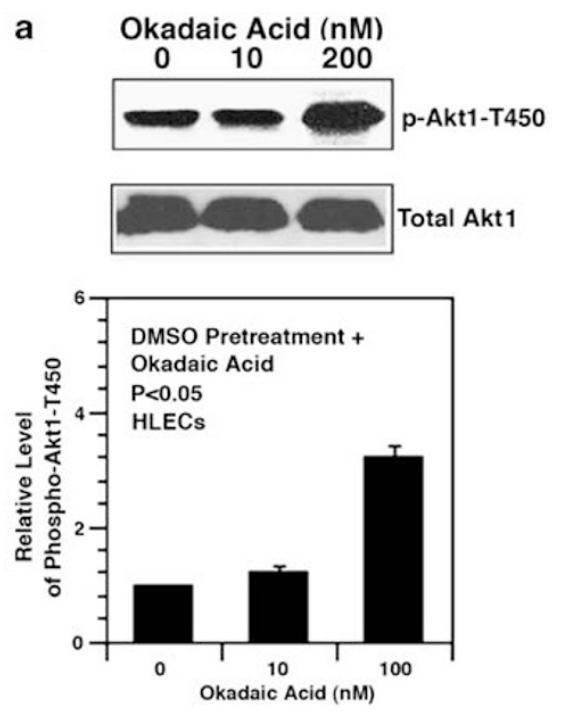

c
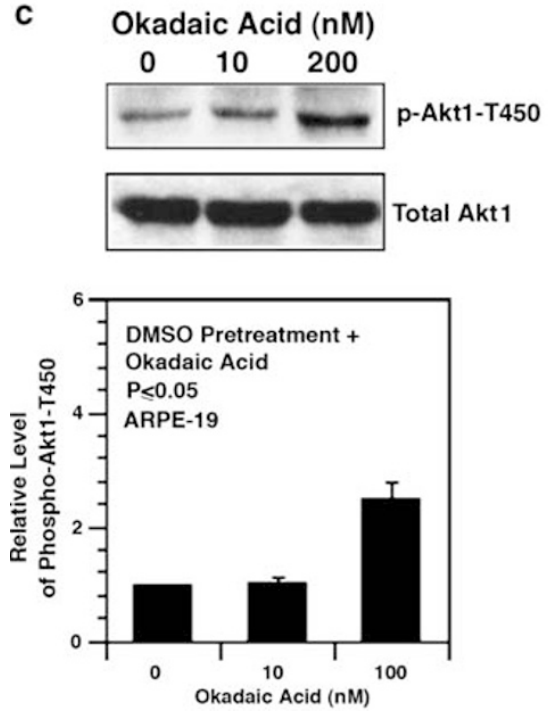

b

Okadaic Acid (nM)


d
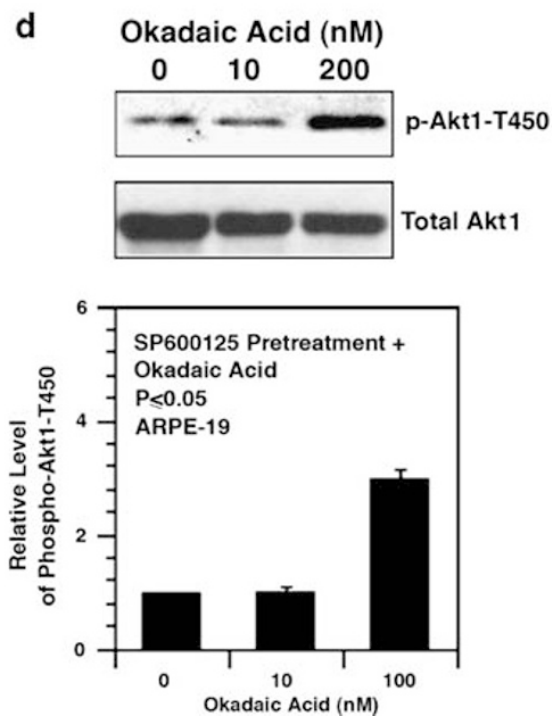

Figure 1 Inhibition of PP-1 but not PP-2A by okadaic acid induces hyperphosphorylation of Akt1 at Thr-450. (a, b) Human lens epithelial cells (HLECs) or (c, d) retinal pigment epithelial cells (ARPE-19) were grown to $95 \%$ confluence, then pretreated with $0.01 \%$ DMSO (panels a and c) or with $1 \mu \mathrm{M} \mathrm{SP} 600125$ (IC $\mathrm{C}_{50}=40 \mathrm{nM}$ for inhibition of JNK1/2) (panels b and d), followed by treatment with 0,10 or $200 \mathrm{nM}$ okadaic acid for $3 \mathrm{~h}$. By the end of the treatment, the cells were harvested for extraction of total proteins that were separated by SDS-PAGE. The blots were then probed with antibodies against either total Akt1 or specific phospho-Akt1 at Thr-450 (Cell Signaling Inc.) overnight. After washing three times with TBST, the blots were further blotted with donkey anti-rabbit IgG for $45 \mathrm{~min}$. After washing, the blots were visualized using GE Healthcare (GE Healthcare, Piscataway, NJ, USA) reagents. The western blots were scanned, and the relative level of pixel density between phospho-Akt1 at T450 and total Akt1 was quantitated. The results are shown in the bottom of the a-d panels. It must be noted that inhibition of PP-1 (by $200 \mathrm{nM}$ okadaic acid) but not PP-2A (by $10 \mathrm{nM}$ okadaic acid) as previously determined ${ }^{5}$ induces hyperphosphorylation of Akt1 at Thr-450, which is hardly affected by the inhibition of JNK1/2 with SP600125. These results suggest that PP-1 but not PP-2A seems to be involved in dephosphorylation of Akt1 at Thr-450. The $P$-value was calculated by comparing the pixel density value from each okadaic acid-treated sample with that from the mock-treated sample

PP-2A catalytic subunits $(\alpha$ and $\beta$ ) using shRNA expression constructs obtained from Open Biosystems Inc., Huntsville, AL, USA (see section 'Experimental Procedures' for details). As shown in Figure $4 a$ and $c$, knockdown of $P P-1 \alpha / \beta$ in HLECs leads to substantial hyperphosphorylation of Akt1 at Thr-450. However, knockdown of PP- $1 \gamma$ or PP-2A $\alpha / \beta$ only caused barely detectable or no enhancement of Akt1 phosphorylation at Thr-450 (Supplementary Figure 3). The dephosphorylation pattern under knockdown of each catalytic subunit of PP-1 or PP-2A displayed no significant change after inhibition of JNK $1 / 2 / 3$ by $1 \mu \mathrm{M}$ of SP600125 (Figure 4b and d). Although establishment of the stable knockdown clones with ARPE-19 cells was unsuccessful (all cells died through apoptosis), transient transfection with knockdown shRNA plasmids for various catalytic subunits of PP-1 and PP-2A showed similar results (data not shown). Together, these results clearly show that $\mathrm{PP}-1 \alpha / \beta$ but not PP $-1 \gamma$ and $\mathrm{PP}-2 \mathrm{~A} \alpha / \beta$ are the major phosphatase isoforms that dephosphorylate Akt1 at Thr-450 in HLECs and ARPE-19 cells. 
a

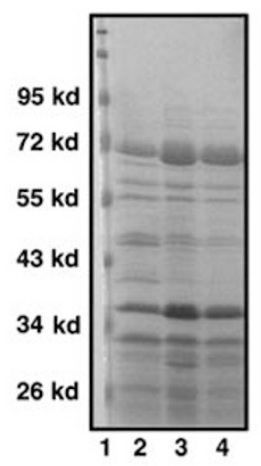

b



C



d

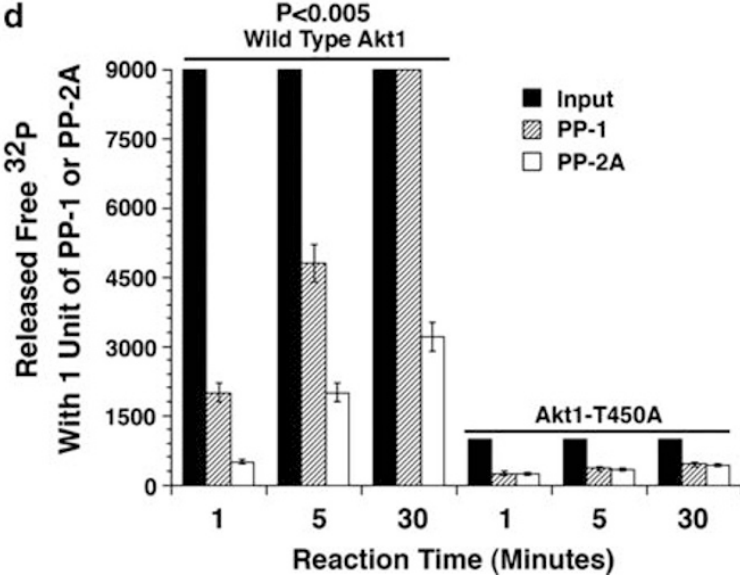

Figure 2 Demonstration that PP-1 dephosphorylates Akt1 at Thr-450 more efficiently than PP-2A does in vitro. (a) Coomassie staining of total GST, GST-Akt1 and GST-Akt1-T450A fusion proteins. (b) Coomassie staining of purified GST, GST-Akt1 and GST-Akt1-T450A fusion proteins. The GST-Akt1 and GST-Akt1-T450A fusion proteins were cleaved with thrombin protease, and Akt1 and Akt1-T450A were further purified and then labeled with JNK1/2, which were used as substrates for the dephosphorylation assays described in $\mathbf{c}$ and $\mathbf{d}$. (panel c) Phosphatase concentration-dependent dephosphorylation by PP-1 and PP-2A. The labeled wild-type Akt-1 (1 $\mu \mathrm{g}$ ) and mutant Akt1 (Akt1-T450A, $1 \mu \mathrm{g}$ ) were incubated with $0.1,1$ or 5 Units of PP-1 (New England Biolabs) or PP-2A (Calbiochem) at $30^{\circ} \mathrm{C}$ in $1 \times$ dephosphorylation buffer for $30 \mathrm{~min}$. By the end of dephosphorylation, the released free ${ }^{32} \mathrm{P}$ was recovered and measured in a scintillation counter as described previously. ${ }^{5,54}$ It must be noted that the amount of free ${ }^{32} \mathrm{P}$ released from labeled Akt1 at each enzyme concentration point by PP-1 was significantly more than that by PP-2A. However, the amount of free ${ }^{32} \mathrm{P}$ released from labeled Akt1-T450A at each enzyme concentration point was similar by PP-1 and PP-2A, which is equal to the blank background level (the blank data were not shown). (Panel d) Time-dependent dephosphorylation assays by PP-1 and PP-2A using $1 \mu$ g substrate and 1 Unit of PP-1 or PP-2A. The dephosphorylation reactions lasted for 1,5 or $30 \mathrm{~min}$. By the end of dephosphorylation, the released free ${ }^{32} \mathrm{P}$ was recovered and measured in a scintillation counter. It must be noted that the amount of free ${ }^{32} \mathrm{P}$ released from labeled Akt1 at each time point by PP-1 was significantly more than that by PP-2A. However, the amount of free ${ }^{32} \mathrm{P}$ released from labeled Akt1-T450A at each time by PP-1 or PP-2A was similar to that from the blank background level (the blank data were not shown). The $P$-value was calculated by comparing the free ${ }^{32} P$-value from each PP-1 or PP-2A reaction with the input

Overexpression of PP-1 $\alpha / \beta$ but not PP-2A $\alpha / \beta$ attenuates Akt1 phosphorylation at Thr-450. To further confirm that $\mathrm{PP}-1 \alpha / \beta$ are the major isoform phosphatases that dephosphorylate Akt1 at Thr-450, we overexpressed each of the five catalytic subunits of PP-1 and PP-2A in HLECs. As shown in Figure $5 a$ and $c$, overexpression of $P P-1 \alpha / \beta$ caused clear hypophosphorylation of Akt1 at Thr-450. In contrast, overexpression of $\mathrm{PP}-1 \gamma$ or $\mathrm{PP}-2 \mathrm{~A} \alpha / \beta$ caused little or no change in the Akt1 phosphorylation status (Supplementary Figure 4). Inhibition of JNK1/2/3 activity by $1 \mu \mathrm{M}$ of SP600125 had little effect on the Akt1 phosphorylation status at Thr-450 after PP-1 overexpression (Figure 5b and d, Supplementary Figure 4). Similar results were obtained in ARPE-19 cells with transient overexpression of the same catalytic subunits. Together, our results further confirm that that $\mathrm{PP}-1 \alpha / \beta$ isoforms act as major phosphatases dephosphorylating Akt1 at Thr-450.

PP-1 dephosphorylation of Akt1 at Thr-450 modulates its regulation of gene expression. Previous studies have shown that Akt1 can indirectly activate NF- $\kappa \mathrm{B}$ through activation of IKKs to phosphorylate $I \kappa B$ for its degradation. ${ }^{8,9}$ In addition, Akt1 also modulates GSK to regulate downstream genes (Figure 6a). To explore whether PP-1 dephosphorylation of Akt1 at Thr-450 may affect its function, we first examined the modulation of Akt1 regulation of gene expression when PP-1 or PP-2A was inhibited under different OA concentrations. As shown in Figure 6b, when the reporter gene, pNF- $\kappa \mathrm{B}$-Luc and $\mathrm{pCl}-\mathrm{Akt} 1$ were cotransfected into HLECs, and then treated with either 10 or $100 \mathrm{nM} \mathrm{OA}$, 



Figure 3 PP-1 interacts with Akt1 within (a, and $\mathbf{c}-\mathbf{f}$ ) human lens epithelial cells (HLECs) and (b, and $\mathbf{g}-\mathbf{j})$ retinal pigment epithelial cells (ARPE-19). (Panel a) Coimmunoprecipitation between Akt1 and PP-1 in HLECs. (Panel b) Coimmunoprecipitation between Akt1 and PP-1 in ARPE-19 cells. (Panel C-f) Confocal immunocytochemistry to detect colocalization of Akt1 and PP-1 in HLECs. (Panel c) FITC from anti-Akt1. (Panel d) Texas Red from anti-PP-1 $\alpha$. (Panel e) Merged image from both FITC and Texas Red signals. (Panel f) The stroked region in Figure $3 e$ shows the overlapping of Akt1 and PP-1 $\alpha$ (yellow color, arrows). (Panels g-j) Colocalization of Akt1 and PP-1 in ARPE-19 cells. (Panel g) FITC from anti-Akt1. (Panel h) Texas Red from anti-PP-1 $\alpha$. (Panel i) Merged image from both FITC and Texas Red signals. (Panel j) The stroked region in Figure $3 i$ showing the overlapping of Akt1 and PP-1 $\alpha$ (yellow color, arrows)

reporter gene activity assays showed that inhibition of PP-1 (by $100 \mathrm{nM} \mathrm{OA}$ ) but not PP-2A (by $10 \mathrm{nM} \mathrm{OA}$ ) substantially increased luciferase activity, indicating enhancement of Akt1 activity. To further confirm this result, we cotransfected the pNF- $\kappa \mathrm{B}$-Luc reporter gene with the empty vector $\mathrm{pCl}-\mathrm{Neo}$, or the construct expressing wild-type Akt1, or its mutants, imitating either constant dephosphorylation (Akt1-T450A) or constant phosphorylation (Akt1-T450D) in HLECs. The different Akt1 constructs were all expressed in HLECs with similar mRNA levels (data not shown) and protein levels (top panel of Figure 6c). When the luciferase activity was analyzed in each case, it was found that overexpression of either Akt1 or Akt1-T450D doubled the luciferase activity (Figure 6d). However, Akt1 mutation at Thr-450 from threonine to alanine abolished exogenous Akt1 function (Figure 6d). The phosphorylation status of the downstream target, GSK-3 $\beta$ at Ser-9, also confirmed a similar conclusion
(Figure 6c). These results indirectly show that dephosphorylation of Akt1 at Thr-450 by PP-1 significantly modulates Akt1 function in regulating gene expression.

Overexpression of PP-1 blocks the positive regulation of gene expression by Akt1. To further confirm that PP-1 modulates Akt1 ability in regulating expression of the downstream genes, we established stable lines expressing Akt1, Akt1-T450A and Akt1-T450D in ARPE-19 cells. We then cotransfected pNF- $\kappa \mathrm{B}$-Luc with $\mathrm{pCl}-\mathrm{Neo}, \mathrm{pCl}-\mathrm{PP}-1 \alpha$ or pCl-PP2A $\alpha$ into the stable clones of ARPE-19 cells. As shown in Figure $7 \mathrm{a}$, overexpression of PP- $1 \alpha$ leads to hypophosphorylation of Akt1 at Thr-450, and also negatively affected the phosphorylation of Akt1 at T-308 and S-473. As a result, phosphorylation of GSK-3 $\beta$ is significantly downregulated. In contrast, overexpression of PP-2A caused a slight decrease in the phosphorylation of Akt1 at 
a
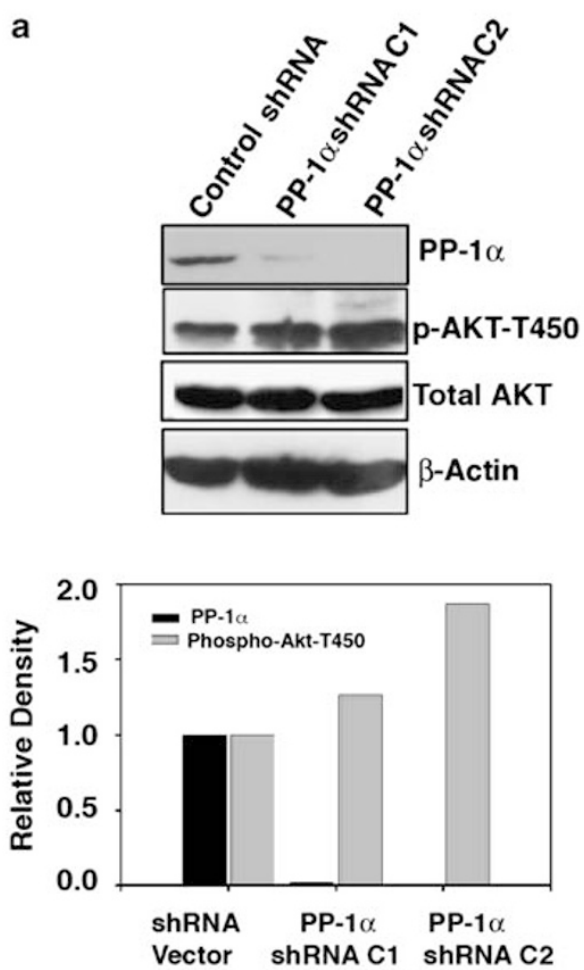

C
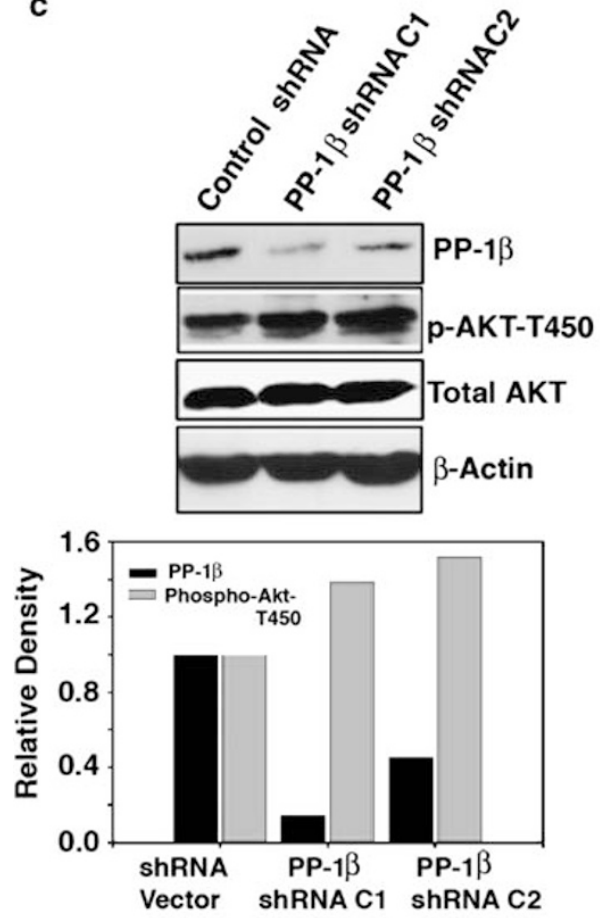

b
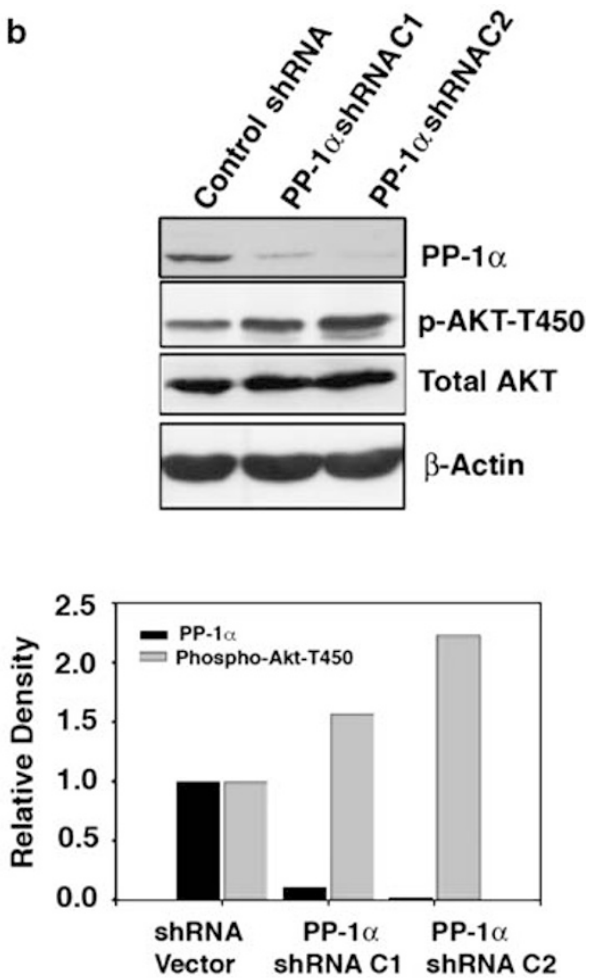

d
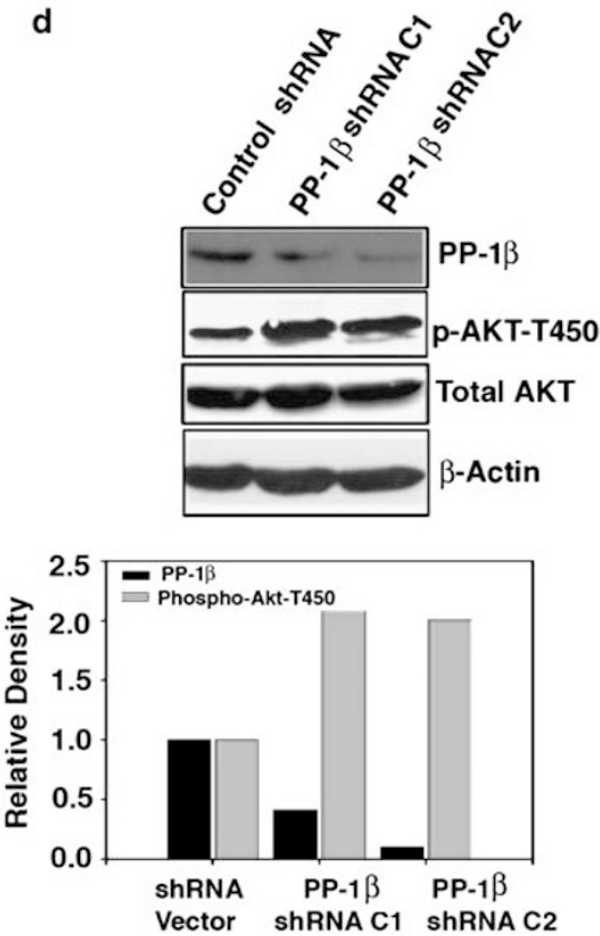

Figure 4 (a, b) Silence of PP-1 $\alpha$ and (c, d) PP-1 $\beta$ by specific shRNAs enhances hyperphosphorylation of Akt1 at Thr-450 in HLECs without (panels a, c) or with (panels b,

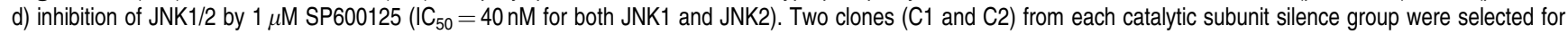
comparison with the mock knockdown. The different silence constructs were obtained from Open Biosystems Inc. and amplified. The different constructs were then transfected into HLEC cells, and stable clones expressing shRNA for each catalytic subunit of PP-1 and PP-2A were established under screening by puromycin (250 $\mathrm{ng} / \mathrm{ml})$ for $4-6$ weeks. The stable clones were first verified by RT-PCR and western blot. It must be noted that knockdown of PP-1 $\alpha$ (panels a, b) and PP-1 $\beta$ (panels $\mathrm{c}, \mathrm{d}$ ) leads to hyperphosphorylation of Akt 1 at Thr-450, which was not affected by SP600125 treatment. The relative silence of PP- $1 \alpha$ and PP-1 $\beta$, as well as the relative enhancement of Akt1 phosphorylation at Thr-450 under each silence condition, was quantitated by determining the relative levels of pixel density. The results are shown at the bottom of a-d panels 
a
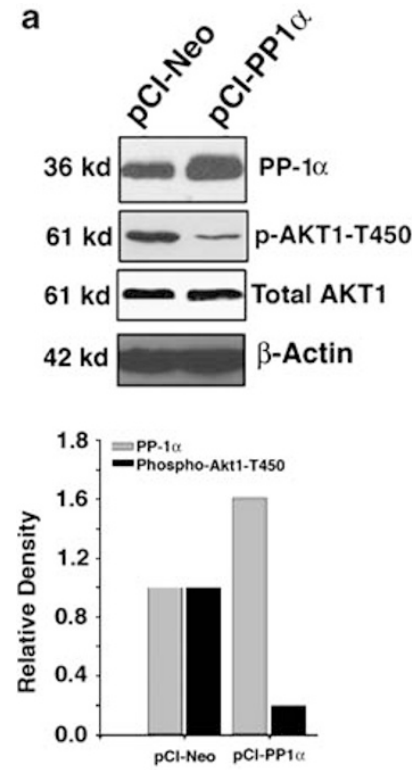

C
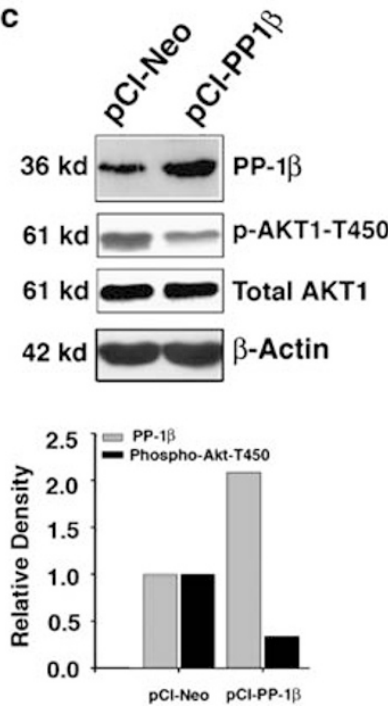

b
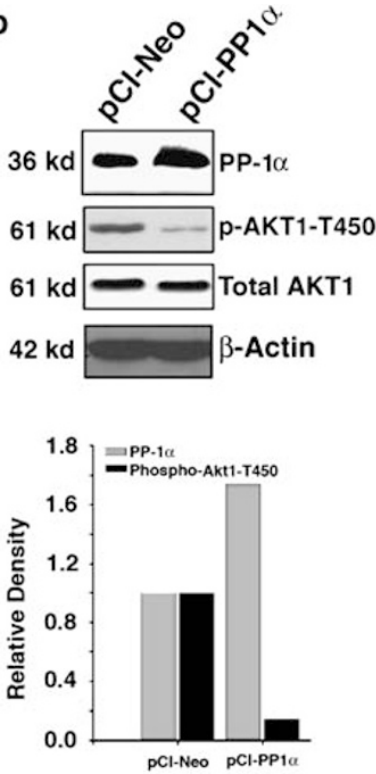

d
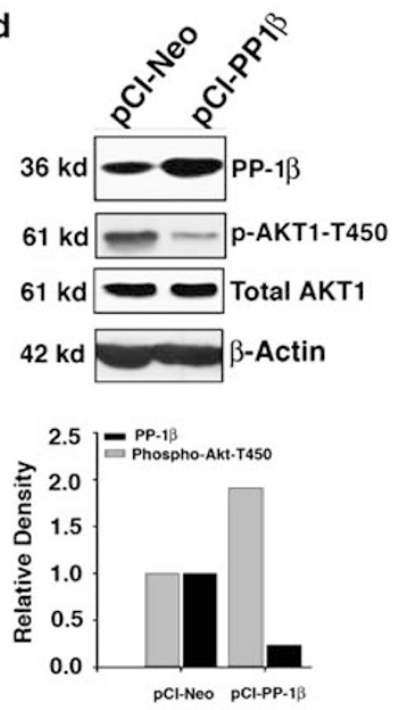

Figure 5 (a, b) Overexpression of PP- $1 \alpha$ and $(\mathbf{c}, \mathbf{d})$ PP- $1 \beta$ in HLECs without (panels a, c) or with (panels b, d) treatment by $1 \mu \mathrm{M}$ of SP600125 (IC $\mathrm{I}_{50}=40 \mathrm{nM}$ for JNK1/2) causes hypophosphorylation of Akt1 at Thr-450. One clone from each catalytic subunit overexpression was selected for comparison with the vectortransfected clone. The overexpression constructs were prepared as described in the section 'Experimental Procedures'. Different constructs were then transfected into HLECs, and stable clones expressing each catalytic subunit of PP-1 and PP-2A were established under screening by $\mathrm{G} 418(400 \mu \mathrm{g} / \mathrm{ml})$ for $4-6$ weeks. The stable clones were first verified by RT-PCR and western blot before experimentation. It must be noted that overexpression of PP- $1 \alpha$ (panels $a, b$ ) and PP- $1 \beta$ (panels $c, d$ ) leads to hypophosphorylation of Akt1 at Thr-450, which was not affected by SP600125 treatment. The relative level of overexpression of PP- $1 \alpha$ and PP-1 $\beta$, or the relative decrease in Akt1 phosphorylation at Thr-450 under each overexpression condition was quantitated by scanning the relative pixel level of each band. The quantitative results are shown at the bottom of panels a-d

Thr-450. However, its role in dephosphorylating Akt1 at $\mathrm{T}-308^{29}$ also leads to hypophosphorylation of Akt1 at S-473 in comparison with vector-transfected cells. When the luciferase activity was measured (Figure 7b), it was found that in the Akt1 stable clone expressing PP-1 $\alpha$ transiently, a
$>50 \%$ decrease in luciferase activity was observed. In the Akt1 stable clone expressing PP-2A $\alpha$ transiently, $\sim 30 \%$ decrease in luciferase activity (Figure $7 \mathrm{~b}$ ) was also observed owing to the fact that PP-2A dephosphorylates Akt1 at T-308 and thus negatively affects the full activation of Akt1 at S-473 (Figure 7a).

Mutation imitating constant dephosphorylation of Akt1 at Thr-450 changes its ability to promote cell survival. It is a well-established fact that the Akt signaling pathway has a very important role in promoting cell survival. ${ }^{8,9,32-34}$ Active Akt1 phosphorylates a panel of antiapoptotic and proapoptotic regulators. $^{8-10}$ To show that PP-1-mediated dephosphorylation of Akt1 at Thr-450 modulates its survivalpromotion ability, we treated Akt1-, Akt1-T450A- and Akt1-T450D-transfected HLECs and ARPE-19 cells with $100 \mathrm{nM}$ staurosporine and examined the viability of the different types of cells (Supplementary Figure 5). As shown in Figure 8a, expression of the exogenous Akt1 enhanced $\sim 30 \%$ viability in HLECs. Expression of the mutant Akt1 imitating constant dephosphorylation, Akt1-T450A, significantly abolished the survival-promotion ability of Akt1. In contrast, expression of the mutant Akt1 imitating constant phosphorylation at Thr-450 (Akt1-T450D) enhanced an additional $24 \%$ more survival than Akt1 expression cells. Similar results were observed with ARPE-19 cells (Figure 8b). Together, these results showed that dephosphorylation of Akt 1 by PP-1 at Thr-450 negatively regulates its survival-promotion ability.

Differential Akt1 expression and activity were observed during mouse eye development. To examine the possible role of active Akt1 in regulating eye development, we examined the expression levels of total Akt1 and phosphoAkt1 at Thr-450, Thr-308 and Ser-473. As shown in Figure 9 (the red fluorescence in row 3), confocal immunofluorescence showed that during mouse eye development, expression of Akt1 was clearly detected in the retina, lens and cornea from 14.5 to 19.5ED. The expression level became slightly increased in the corresponding eye tissues as development moved from 14.5 to 19.5 ED. Phosphorylation of Akt1 at Thr-450 (green fluorescence in row 5 of Figure 9), Thr-308 (green fluorescence in row 6 of Figure 9) and Ser-473 (green fluorescence in row 7 of Figure 9 ) is the highest at 14.5ED and became slightly decreased from 14.5 to $17.5 \mathrm{ED}$. At 19.5 ED, although phosphorylation of Akt1 at Thr-450 was still detectable, the signals of phosphorylation fluorescence at Thr-308 and Ser-473 became much weaker (Figure 9). Together, our results showed that both the expression and phosphorylation status of Akt1 are developmentally regulated, suggesting its role in regulating eye tissue differentiation.

Akt1 mutation imitating constant dephosphorylation at Thr-450 (Akt1-T450A) abolishes FGF-induced differentiation. Previous studies have shown that bFGF induces lens differentiation under both in vitro and in vivo conditions. $^{35-40}$ To show that PP-1-mediated dephosphorylation may modulate the differentiation-promotion 
a

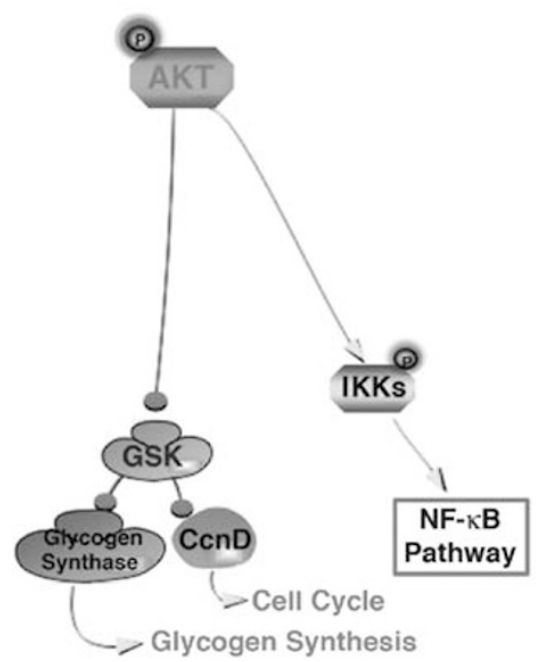

C

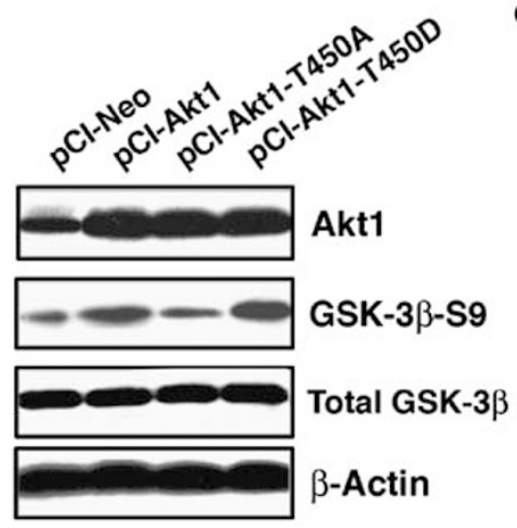

b
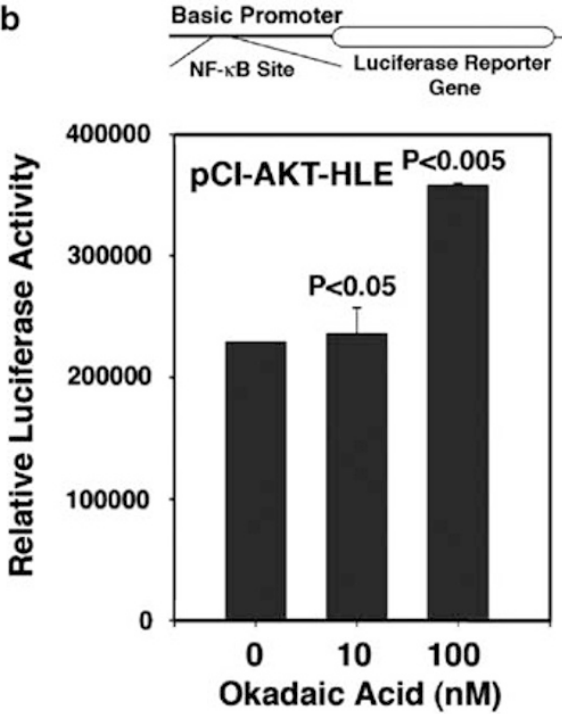

d



Figure 6 Inhibition of PP-1 by (b) okadaic acid or (c and d) overexpression of Akt1 or Akt1 mutant imitating constant phosphorylation at Thr-450 in HLECs positively modulates Akt1 function in regulating gene expression. (a) Diagram showing two downstream pathways subjected to Akt1 regulation. (Panel b) Treatment of HLECs with $100 \mathrm{nM}$ okadaic acid (inhibiting PP-1 and PP-2A) substantially enhances the reporter gene activity driven by a mini-promoter containing an NF- $\kappa$ B binding site. In contrast, inhibition of PP-2A alone by $10 \mathrm{nM}$ okadaic acid only slightly enhances the luciferase reporter gene activity. Inhibition of PP-1 caused hyperphosphorylation of Akt1 at Thr-450, priming Akt1 for further activation by PDK1 and other kinases. Activated Akt1 activates IKK $\beta$ to phosphorylate $I_{\kappa} B$ and thus releases NF- $\kappa B$ for translocation into the nucleus to activate the reporter gene expression. (Panel c) Western blot analysis of the expression levels of pCl-Neo vector, pCl-Akt1, pCl-Akt1-T450A and pCl-Akt1-T450D and also the phospho-GSK-3 $\beta$ at Ser-9 in HLECs. It must be noted that the overexpression of wild-type Akt1 or Akt1-T450D enhanced phosphorylation of GSK-3 $\beta$ at Ser-9. (Panel d) Overexpression of Akt1 distinctly enhanced the reporter gene activity compared with expression of the empty vector. Overexpression of the mutant Akt1, Akt1-T450A, imitating constant dephosphorylation of Akt1 at Thr-450, abolished Akt1 function in positively regulating gene expression because of the absence of exogenous Akt1 activation. In contrast, overexpression of Akt1-T450D, imitating constant phosphorylation of Akt1 at Thr-450, also upregulates the luciferase reporter gene activity as did the wild-type Akt1. $P$-value was calculated by comparing the luciferase activity from okadaic acid-treated samples with the DMSO-treated sample (panel b), or that from Akt1, Akt1-T450A or Akt1-T450D overexpression samples with the pCl-neo vector-transfected sample (panel d)

ability of Akt1, we treated Akt1-, Akt1-T450A- and Akt1T450D-transfected HLECs with $50 \mathrm{ng} / \mathrm{ml}$ bFGF for 0,2 and 5 days, respectively. As shown in Figure 10a, bFGF induced lentoid formation in both Akt1- and Akt1-T450D-transfected cells but not in T450A-transfected cells. Western blot analysis further showed that T450A mutation suppressed bFGF-induced activation of Akt1 (Figure 10b), and also abolished expression of the differentiation marker, $\beta$-crystallin, or significantly attenuated expression of $\mathrm{N}$-cadherin, another differentiation marker in lens. Thus, a mutant imitating constant dephosphorylation of Akt1 at Thr-450 by PP-1 abolishes its role of promoting differentiation.
PP-1 modulates Akt1-mediated FGF regulation of lens cell differentiation. To further confirm that the PP-1 dephosphorylation of Akt1 at Thr-450 modulates cell differentiation in the Akt1 stable clone, we transiently expressed PP- $1 \alpha$ and then explored the PP- $1 \alpha$ effect on FGF-induced differentiation. To do so, both pCl-AKT1/ pCl-Neo- $\alpha$ TN4-1 and pCl-AKT1/pCl-PP-1 $\alpha-\alpha$ TN4-1 cells were treated with $50 \mathrm{ng} / \mathrm{ml} \mathrm{bFGF}$ for $0-5$ days and the differentiation status was examined. As shown in Figure 11c, FGF induced lentoid formation of the Akt1-expressing cells within 5 days; however, in both Akt 1 and PP- $1 \alpha$ coexpression cells, bFGF treatment did not induce lentoid formation 



Figure 7 PP-1 dephosphorylation of Akt1 also affects its ability to regulate gene expression in ARPE-19 cells. Coexpression of wild-type Akt1 with pCl-Neo or $\mathrm{pCl}-\mathrm{PP}-1 \alpha$ or $\mathrm{pCl}-\mathrm{PP}-2 \mathrm{~A} \alpha$ changes the phosphorylation patterns of Akt1 at Thr- 450 , Thr-308 and Ser-473, and (a) the downstream target GSK-3 $\beta$ phosphorylation status at Ser-9 residue and (b) the profile of the luciferase reporter gene activity. In the case of coexpression of wild-type Akt1 with $\mathrm{pCl}-\mathrm{Neo}, \mathrm{pCl}-\mathrm{PP} 1 \alpha$ or $\mathrm{pCl}-\mathrm{PP} 2 \mathrm{~A} \alpha$, both PP-1 and PP-2A downregulate GSK-3 $\beta$ phosphorylation status and also reporter gene activity with differential mechanisms. Expression of PP-1 attenuates Akt1 phosphorylation at Thr-450 and thus negatively regulates Akt1 activation by PDK1 and other kinases. However, expression of PP-2A inactivates Akt1 through dephosphorylation at Thr-308. The $P$-value was calculated by comparing the luciferase activity from cotransfection of Akt1 and PP-1 $\alpha$, or Akt1 and PP-2A $\alpha$ with that from the cotransfection of Akt1 plus the $\mathrm{pCl}$-neo vector (panel b)

(Figure 11d). Western blot analysis of the proteins extracted from the two types of cells treated by bFGF for $0,1,24,48$ and $120 \mathrm{~h}$ showed consistent results. As shown in Figure 11e, bFGF induced Akt1 activation and a relatively constant level of $\alpha \mathrm{B}$-crystallin expression during the whole treatment period and also $\beta$-crystallin expression on days 4 and 5 in $\mathrm{pCl}-\mathrm{AKT} 1 / \mathrm{pCl}-\mathrm{Neo}-\alpha \mathrm{TN} 4-1$ cells, confirming the differentiation status induced by bFGF. In contrast, in $\mathrm{pCl}-\mathrm{AKT} 1 / \mathrm{pCl}-$ PP- $1 \alpha-\alpha$ TN4-1 cells, expression of PP- $1 \alpha$ blocked Akt1 activation and also suppressed expression of $\beta$-crystallin. These results suggest that by negatively regulating Akt1 activation, PP-1 prevents bFGF-induced lens cell differentiation.

\section{Discussion}

In this study, we showed the following: (1) PP-1 is more efficient than PP-2A in dephosphorylating Akt1 at Thr-450 in the in vitro dephosphorylation assays; (2) PP-1 and Akt1 can form an interacting complex within HLECs and ARTPE-19 cells; (3) Inhibition of PP-1 but not PP-2A leads to hyperphosphorylation of Akt1 at Thr-450; (4) knockdown of PP-1 $\alpha / \beta$ but not PP- $1 \gamma$ or PP-2A $\alpha / \beta$ results in hyperphosphorylation of Akt 1 at Thr-450; (5) Overexpression of PP-1 $\alpha / \beta$ but not PP-1 $\gamma$ or $\mathrm{PP}-2 \mathrm{~A} \alpha / \beta$ causes hypophosphorylation of Akt1 at Thr-450; (6) Mutation imitating constant dephosphorylation of Akt1 at Thr-450 or coexpression of PP-1 and Akt1 leads to downregulation of Akt1 function in promoting gene expression, cell survival and differentiation. These results confirm that PP-1 but not PP-2A directly dephosphorylates Akt1 at Thr-450 in both HLECs and retinal pigment epithelial cells. Dephosphorylation
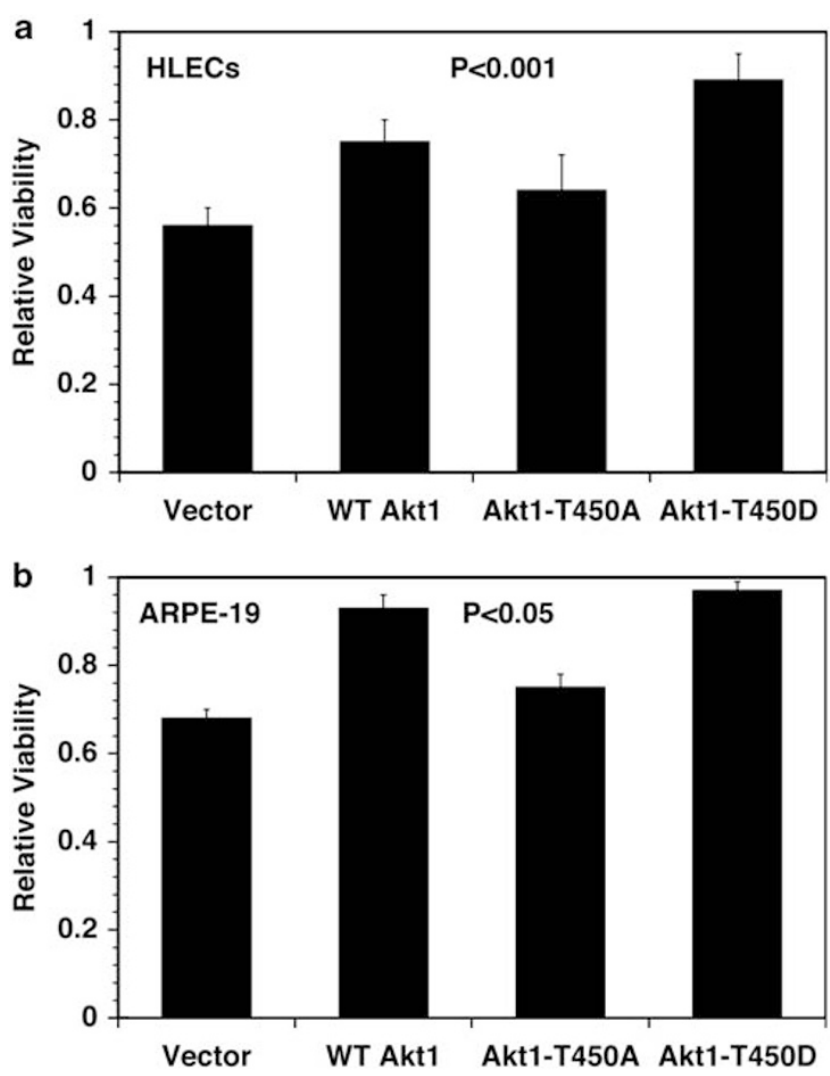

Figure 8 Mutant Akt1, Akt1-T450A, imitating constant dephosphorylation by PP-1 lost most of the survival-promotion ability of wild-type Akt1. (a) Stable HLECs and (b) ARPE-19 clones expressing pCl-Neo vector, pCl-AKT1, pCl-AKT1-T450A or pCl-AKT1-T450D were treated with a single dose of $100 \mathrm{nM}$ staurosporine for $6 \mathrm{~h}$ and then harvested for cell flow cytometry analysis as described previously (also see Supplementary Figure 4). ${ }^{6,63}$ It must be noted that AKT1-T450D-transfected cells showed the highest level of survival. In contrast, the AKT1-T450A-transfected cells displayed a level of apoptosis similar to vector-transfected cells, suggesting that Akt1-T450A lost most of the survival-promotion functions of AKT1. P-value was calculated by comparing the viability of wild-type Akt1 or mutant Akt1(T450A or T450D)-transfected cells with that of vector-transfected cells

of Akt1 by PP-1 modulates its functions in regulating gene expression, cell survival and differentiation (Figure 12).

PP-1 is a major phosphatase that dephosphorylates Akt1 at Thr-450. The Akt/PKB signaling pathway has a very important role in promoting cell proliferation, survival and differentiation. ${ }^{8,9,14}$ On action by various growth factors, the receptor-tyrosine kinase becomes activated and then activates two important pathways. First, the JNK kinase pathway is activated, ${ }^{41}$ which can prime the Akt1 kinase by phosphorylating Thr-450. ${ }^{15,16}$ At the same time, the PI3K kinase pathway is activated that converts PIP2 into PIP3.,9 PIP3 recruits both Akt1 and PDK1 to the plasma membrane through the $\mathrm{PH}$ domain. PDK1 then phosphorylates Akt1 at Thr-308 to partially activate Akt1. After phosphorylation, the C terminal of the Akt1 kinase becomes unfolded and exposes the Ser-473 residue of Akt1, which can be phosphorylated by the putative PDK2 kinase or several other kinases ${ }^{21,23}$ to achieve its full activation. When the growth factors are withdrawn, inactivation of the Akt pathway occurs at two 


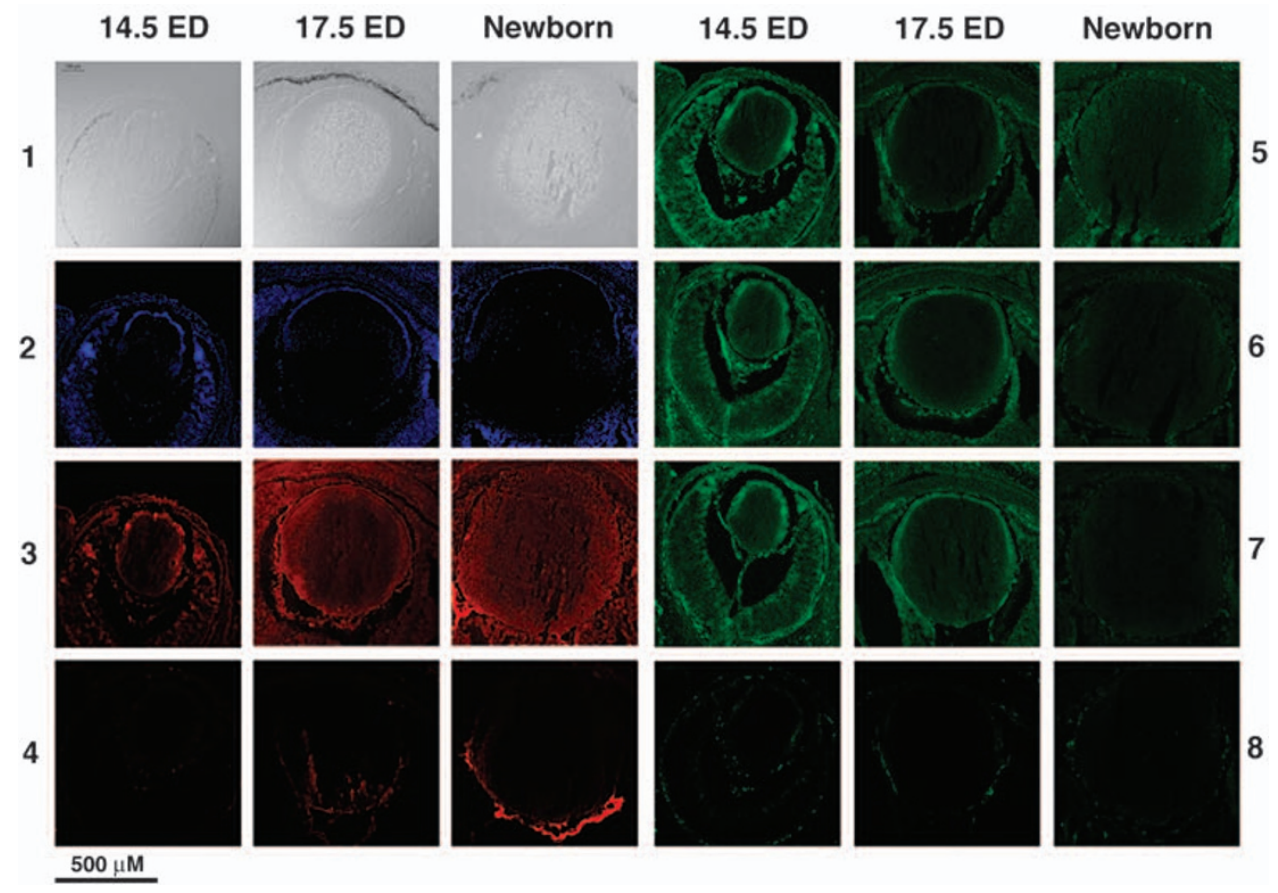

Figure 9 Confocal immunocytochemistry analysis of total and phospho-AKT1 during the development of mouse eye. The mouse eye tissues were fixed and sectioned as described in the section 'Experimental Procedures'. The sections were washed and blocked with $500 \mu$ l of $5 \%$ normal goat serum (Sigma) in PBS for $1 \mathrm{~h}$ at room temperature and then incubated overnight in $400 \mu \mathrm{l}$ of diluted antibodies $(1: 100)$ in a humidified chamber at $4{ }^{\circ} \mathrm{C}$. The sections were then washed, followed by incubation in $400 \mu \mathrm{l}$ of secondary antibodies linked to Texas Red (total Akt1, panel 3) or FITC (phospho-Akt1 at Thr-450 (panel 5), phospho-Akt1 at Thr-308 (panel 6), and phospho-Akt1 at Ser-473 (panel 7)) from Vector Laboratories at 1:1000 dilution in blocking solution for $1 \mathrm{~h}$ in the absence of visible light. After incubation, sections were washed and then observed under a Zeiss confocal fluorescence microscope. For negative controls, the sections were treated in the same manner, except that the primary antibody was replaced by normal serum (row 4, control for total Akt1; or row 8, control for phospho-Akt1). Row 1 shows morphology of bright field image; row 2 displays nuclei from Hoechst staining. It must be noted that from 14.5 to $19.5 \mathrm{ED}$, the signal for total Akt1 was slightly increased. The phospho-Akt1 signals, regardless at T450, T308 or Ser-473, were gradually decreased from 14.5 to 17.5 ED. At 19.5 ED, however, the signal for phospho-Akt1 at Thr-450 is relatively stronger than that at Thr-308 and Ser-473; consistent with this, phosphorylation of Akt1 at Thr-450 is important for its further activation through phosphorylation at Thr-308 and Ser-473 by PDK1 and other kinases ${ }^{15,16,21-23}$

levels. First, the PTEN tyrosine phosphatase will convert PIP3 into PIP2 to prevent further activation of the PDK kinases. ${ }^{24,25}$ Second, the $\mathrm{PH}$ domain phosphatases will dephosphorylate Akt1 at Ser-473 and possibly at Thr$308 .^{26,27}$ In addition, recent studies have shown that PP-2A directly dephosphorylates Akt1 at Thr-308 to further inactivate Akt1. ${ }^{16,28,29}$ For Akt1 to become completely inactivated, the Thr-450 of Akt1 needs to be dephosphorylated. In this study, we have presented both in vitro and physiological evidence to show that PP-1 is the major phosphatase that dephosphorylates Akt1 at Thr-450. First, PP-1 and Akt1 form a complex and are colocalized in both the cytoplasm and the nucleus. Second, inhibition or knockdown of PP-1 but not PP-2A leads to hyperphosphorylation of Akt1 at Thr-450. Third, overexpression of PP $-1 \alpha / \beta$ but not PP-2A $\alpha / \beta$ causes hypophosphorylation of Akt1 at Thr-450. Thus, in both lens epithelial cells and retina pigment epithelial cells, PP-1 is the major phosphatase that dephosphorylates Akt1 at Thr-450 to completely inactivate it. Among the three different catalytic subunits, our data also showed that the $\alpha$ - and $\beta$-isoforms but not the $\gamma$-isoform are mainly involved in dephosphorylation of Akt1at Thr-450 (Figures 4 and 5). Dephosphorylation of Akt1 at Thr- 450 by PP-1 has significant effects on Akt1 functions that are discussed below.
PP-1 dephosphorylation of Akt1 at Thr-450 modulates the functions of the Akt1 signaling pathway. Previous studies have shown that the Akt signaling pathway has an important role in regulating gene expression. ${ }^{8,9}$ Akt1 does so through modulation of the functions of multiple transcription factors, including FKHR, AFX and NF- $\kappa \mathrm{B}$, etc. ${ }^{8}$ For example, by activating $\mathrm{IKK} \beta$ through phosphorylation, Akt1 indirectly removes the inhibitory subunit $\mathrm{I}_{\kappa} \mathrm{B}$ from the nuclear factor NF- $\kappa$ B complex and thus allows its nuclear translocation to positively regulate the expression of target genes. In this study, we used a luciferase reporter gene driven by a minipromoter containing an $\mathrm{NF}-\kappa \mathrm{B}$ binding site to explore modulation of Akt1-regulated gene expression by PP-1. We show that inhibition of PP-1 activity by OA or mutation of Akt1 imitating constant phosphorylation at Thr-450 significantly enhanced the luciferase reporter gene activity (Figures 6 and 7). In contrast, overexpression of PP- $1 \alpha$ or the mutation imitating constant dephosphorylation of Akt1 at Thr-450 significantly downregulates activity of the luciferase reporter gene (Figures 6 and 7). In addition, expression of the mutant imitating constant dephosphorylation (pCl-AKT1-T450A) also distinctly attenuates Ser-9 phosphorylation of GSK-3 $\beta$ (Figure 6c). Together, these results show that dephosphorylation of Akt 1 at Thr-450 by PP-1 significantly modulates its function in regulating gene expression. In this 


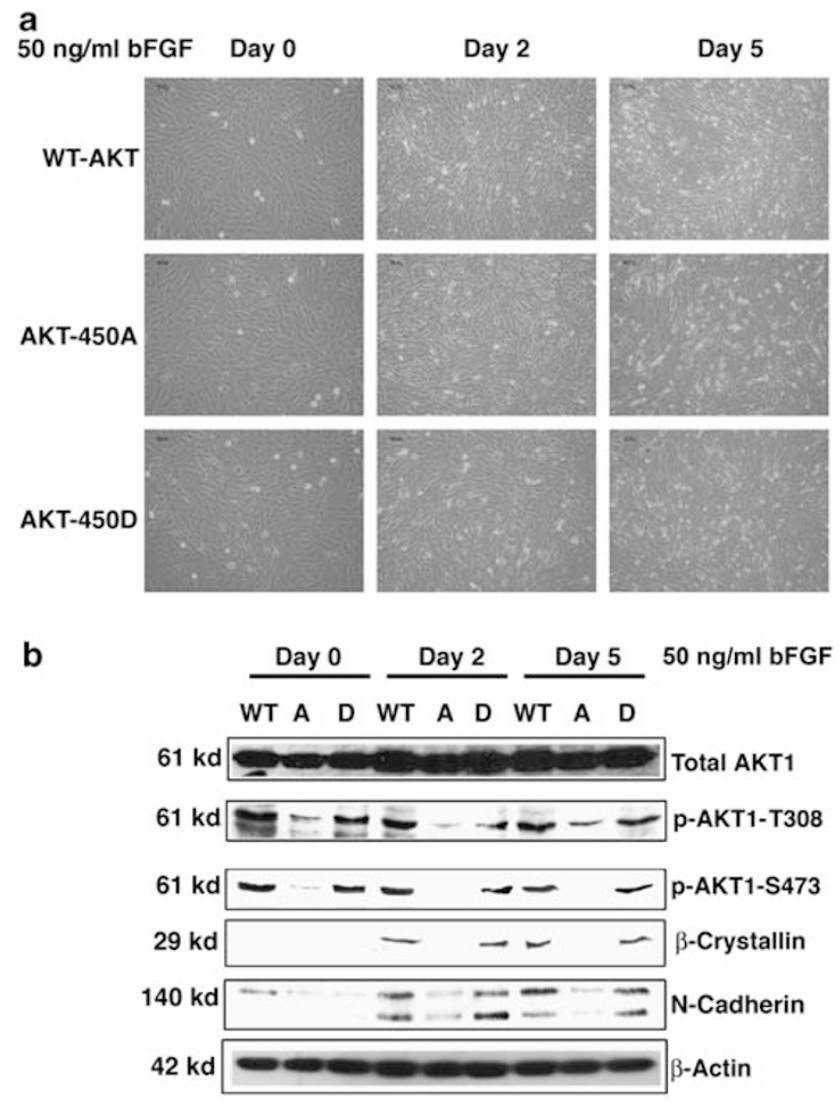

Figure 10 Mutant Akt1, Akt1-T450A, imitating constant dephosphorylation by PP-1 suppresses Akt1-mediated cell differentiation. Stable HLEC clones expressing pCl-AKT1, pCl-AKT1-T450A or pCl-AKT1-T450D were treated with $50 \mathrm{ng} / \mathrm{ml} \mathrm{bFGF}$ for 0,2 and 5 days, and the morphology of each group of cells was monitored with light microscopy. At the same time, the treated cells at different stages were harvested for extraction of total proteins that were used for analysis of Akt expression level and phosphorylation status, and also expression of the differentiation markers $\beta$-crystallin and $\mathrm{N}$-cadherin. It must be noted that both AKT1- and AKT1-T450D-transfected cells can form lentoid after bFGF induction. (a) This is suppressed in the AKT1-T450A-transfected cells. (b) Western blot analysis showed that in AKT1 and AKT1-T450D-transfected cells, Akt1 was fully activated and the differentiation markers $\beta$-crystallin and $\mathrm{N}$-cadherin were clearly detected. In contrast, in AKT1-T450A-transfected cells, activation of AKT1 was largely suppressed and expression of the differentiation markers was also inhibited. These results suggest that mutation imitating constant dephosphorylation by PP-1 interferes with Akt1-mediated promotion of differentiation

study, we also observed that although overexpression of PP-2A does not contribute much to the phosphorylation status of Akt1 at Thr-450 (Figure 5), it also downregulates the reporter gene activity to some degree as PP-1 does. The downregulations observed in both cases are derived from different mechanisms. In the case of PP- $1 \alpha$ overexpression, it dephosphorylates Akt1 at Thr-450 to block Akt1 activation. In contrast, overexpression of PP-2A dephosphorylates Akt1 at Thr-308 to inactivate it. ${ }^{16,28,29}$

The Akt signaling pathway has a key role in promoting cell survival. ${ }^{8,9,16,32-34}$ Dephosphorylation of Akt1 at Thr-450 by PP-1 also affects its survival-promotion ability. In this study, we show that in both lens epithelial cells and retinal pigment epithelial cells, Akt1 mutation imitating
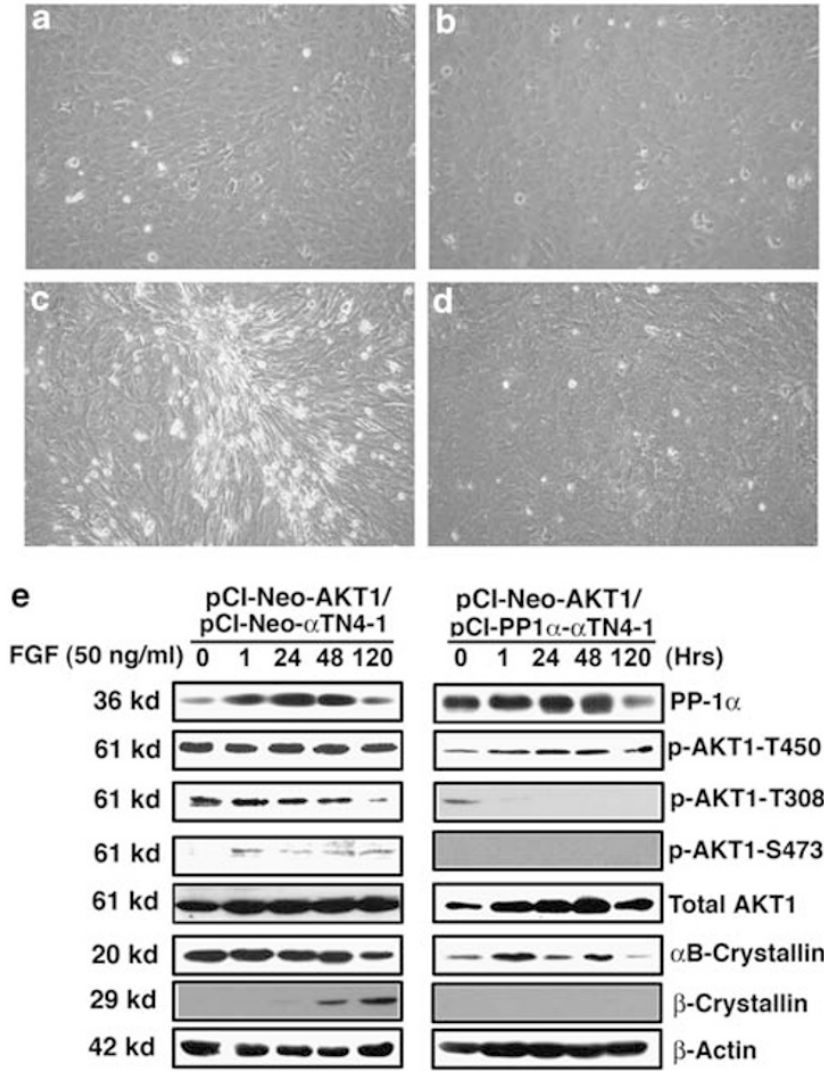

pCl-Neo-AKT1/ pCl-PP1 $\alpha-\alpha$ TN4-1 \begin{tabular}{llllll}
\hline 0 & 1 & 24 & 48 & 120 & (Hrs)
\end{tabular}

Figure 11 PP-1 modulates Akt1 function in mediating bFGF-induced cell differentiation. The $\mathrm{pCl}-\mathrm{AKT} 1 / \mathrm{pCl}-\mathrm{neo}$ or $\mathrm{pCl}-\mathrm{AKT} 1 / \mathrm{pCl}-\mathrm{PP}-1 \alpha$ co-transfected stable clones were treated with $50 \mathrm{ng} / \mathrm{ml}$ bFGF for $0-5$ days. (a) Confluent $\mathrm{pCl}-\mathrm{Akt} 1 / \mathrm{pCl}-\mathrm{Neo}-\alpha \mathrm{TN} 4-1$ cells after bFGF treatment for 0 day. (b) Confluent $\mathrm{pCl}-$ Akt $1 / \mathrm{pCl}-\mathrm{PP}-1 \alpha-\alpha \mathrm{TN} 4-1$ cells after bFGF treatment for 0 day. (c) Confluent $\mathrm{pCl}-$ Akt1/pCl-Neo- $\alpha$ TN4-1 cells after bFGF treatment for 5 days. (d) Confluent $\mathrm{pCl}$-Akt1/ pCl-PP- $1 \alpha-\alpha$ TN4-1 cells after bFGF treatment for 5 days. (e) pCl-Akt $1 / \mathrm{pCl}-\mathrm{Neo}-$ $\alpha \mathrm{TN} 4-1$ cells (left panels) and pCl-Akt1/pCl-PP- $1 \alpha-\alpha \mathrm{TN} 4-1$ cells (right panels) were treated with $50 \mathrm{ng} / \mathrm{ml}$ bFGF for $0,1,24,48$ and $120 \mathrm{~h}$ and then harvested for extraction of total proteins that were then subjected to western blot analysis as described in the section 'Experimental Procedures'. It must be noted that in $\mathrm{pCl}$ Akt $1 / \mathrm{pCl}-\mathrm{Neo}-\alpha \mathrm{TN} 4-1$ cells, bFGF induced lentoid formation within 5 days of treatment (panel $\mathrm{c}$ ), and the differentiation nature was confirmed by expression of the lens differentiation marker, $\beta$-crystallin (left panels of e). However, expression of PP- $1 \alpha$ suppressed bFGF-induced lentoid formation (panel d) and $\beta$-crystallin expression because of the lack of Akt1 activation (right panels of $e$ )

constant dephosphorylation at Thr-450 significantly attenuated its ability to resist on staurosporine-induced apoptosis (Supplementary Figure 5 and Figure 8). On the other hand, in these cells, Akt1 mutation imitating constant phosphorylation at Thr-450 enhances its ability to prevent staurosporineinduced apoptosis. Our results are consistent with those of earlier studies. ${ }^{16}$ Thus, dephosphorylation of Akt1 at Thr-450 by PP-1 negatively regulates its survival-promotion activity.

The Akt1 signaling pathway is known to mediate cell differentiation. ${ }^{35,36,42-45}$ In this study, we also show that during mouse eye development, both the expression and phosphorylation of Akt1 at Thr-450, Thr-308 and Ser-473 are clearly detected at 14.5 and 17.5ED. At 19.5ED, although expression and phosphorylation of Akt1 at Thr- 450 are still 
clearly detectable, phosphorylation of Akt1 at Thr-308 and Ser-473 at 19.5ED becomes less obvious. This is not surprising considering that the Akt pathway is important for protecting tissue cells during rapid growth of the embryonic eye. Consistent with the role of Akt1 mediating ocular tissue differentiation is our in vitro results that FGF-induced differentiation of mouse lens epithelial cells requires Akt1 signaling (Figures 10 and 11). Overexpression of the mutant Akt1, Akt1-T450A in HLECs or overexpression of PP-1 $\alpha$ in Akt1-expressing mouse lens epithelial cells prevents both Akt1 activation and also lens cell differentiation induced by FGF (Figures 10 and 11). Thus, through dephosphorylation of Akt1 at Thr-450, PP-1 also modulates Akt1 function in mediating cell differentiation.

Together, our results show that PP-1 negatively modulates Akt 1 functions in regulating gene expression, cell survival and differentiation through dephosphorylation at Thr-450.

PP-1 can regulate multiple signaling pathways to control cell death and differentiation. As discussed earlier, accumulated evidence shows that protein dephosphorylation at the serine and threonine residues on proteins has important roles in regulating both cell death and cell differentiation. ${ }^{1,2}$ PP-1 regulates these cellular processes through the regulation of several major signaling transduction pathways. First, as we have shown in this study, PP-1, through its engagement in dephosphorylation of Akt at Thr-450, can regulate Akt activity and also its downstream targets, both GSK-3 $\beta$ and IKK, to suppress differentiation but promote apoptosis (Figure 12). Second, the Wnt/ $\beta$-catenin signaling pathway has a pivotal role in modulating cellular proliferation, differentiation, tissue organization and embryonic development. A recent study has shown that PP-1 is involved in modulating the $\mathrm{Wnt} / \beta$-catenin pathway. ${ }^{46} \mathrm{PP}-1$ is found to interact with Axin and thus dephosphorylates it to activate the $\mathrm{Wnt} / \beta$-catenin pathway. This activation can be blocked by the endocytic adaptor disabled (Dab2) protein through direct interaction between PP-1 and Dab2. ${ }^{46}$ Third, $\mathrm{PP}-1$ can regulate the TGF $\beta$ signaling pathway. PP-1 negatively regulates this pathway through the direct dephosphorylation of TGF $\beta$ type I receptor (TGF $\beta \mathrm{RI})$. Under stress conditions such as UV irradiation, Smad7 is induced to interact with growth arrest and DNA damage protein, GADD34, which recruits PP-1 to TGF $\beta$ RI and dephosphorylates the latter to inhibit TGF $\beta$-induced cell-cycle arrest and mediate TGF $\beta$ resistance. ${ }^{47}$ Fourth, PP-1 can directly modulate NF- $\kappa \mathrm{B}$ activation pathway, a major pathway mediating survival and differentiation in both immune and other systems. PP-1 regulates this pathway through interactions with the CUE domain-containing 2 (CUED2) protein through GADD34, recruits PP-1 to dephosphorylate IKK and thus inactivates the $\mathrm{NF}-\kappa \mathrm{B}$ pathway. ${ }^{48}$ Finally, PP-1 modulates the unfolded protein response (UPR) pathway. Endoplasmic reticulum stress such as the protein misfolding activates UPR, which includes dephosphorylation of the eukaryotic initiation factor $2 \alpha($ elF $2 \alpha)$ and inhibition of overall protein synthesis. On the other hand, UPR leads to the translation of a subset of mRNAs including those coding ATF4, CHOP and BiP. ${ }^{49-52}$ The upregulation of ATF4 induces transcription of

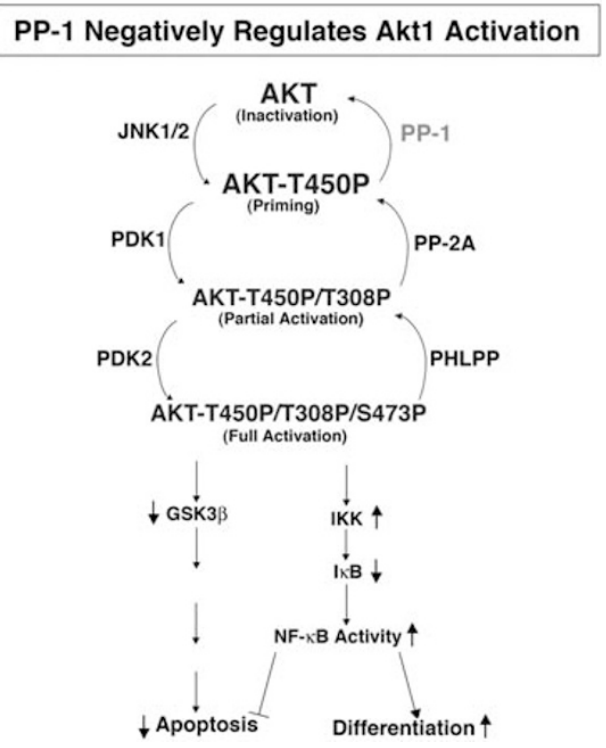

Figure 12 Diagram showing PP-1 negatively regulating Akt-1 activation. Akt1 is first primed through phosphorylation at Thr-450 in the cytosol by the stress-activated protein kinase, JNK1/2, under certain conditions. After activation by the ligandregulated receptor-tyrosine kinases, the phosphoinositide-3-kinase (PI3K) generates phosphoinositol-3,4,5-triphosphate (PIP3), which recruits phosphoinositide-dependent kinase 1 (PDK1) and Akt1 to the membrane through its PH domain to allow PDK1 phosphorylating Akt1 at Thr-308, thus causing a confirmation change of Akt1 to expose its C-terminal hydrophobic motif. Finally, after the configuration change, Akt1 may either undergo auto-phosphorylation at Ser-473 or become phosphorylated by a second kinase referred to as PDK2 or other kinases at Ser-473 to achieve its full activation. Activated Akt1 can phosphorylate GSK-3 $\beta$ to inactivate its activity, and at the same time, activate $\operatorname{IKK} \beta$ to phosphorylate $I_{\kappa} B$ and release $\mathrm{NF}-\kappa \mathrm{B}$ into the nucleus. As a result of these actions, Akt1 can suppress apoptosis and promoter cell differentiation. On the other hand, Akt1 is first dephosphorylated by PHLPP at Ser-473, and later by PP-2A at Thr-308. We show here that PP-1 specifically dephosphorylates Akt1 at Thr-450 to completely inactivate Akt1

downstream genes such as GADD34, which recruits PP-1 to dephosphorylated elF $2 \alpha$ and thus attenuates the UPR response. ${ }^{49-52}$

Besides the regulation of the above-mentioned major signaling pathway, PP-1 also modulates differentiation and cell death through dephosphorylation of individual molecules. For example, during myogenic differentiation of embryonic muscle cells, PP-1 has an important role. The myristoylated alanine-rich $C$ kinase substrate (MARCKS) translocates from the cytosol to the plasma membrane when mononucleated myoblasts fuse to form multinucleated myotubes. Dephosphorylation of MARCKS by PP-1 is important for myogenic cell fusion. A mutation preventing MARCKS phosphorylation facilitates its translocation and results in the promotion of cell fusion. ${ }^{53}$ Pax-6 is an important transcriptional factor that mediates control on both brain and eye development. Our recent study shows that PP-1 directly dephosphorylates Pax-6 to attenuate its transcriptional activity in HLECs. ${ }^{54}$

The two major tumor suppressors, p53 and Rb, are important in regulating cell death. p53 regulates apoptosis either through direct interaction with antiapoptotic regulators or through control of a panel of downstream apoptosis genes. ${ }^{55-58}$ We have recently shown that PP-1 can dephosphorylate p53 at multiple sites to attenuate its transcriptional 
activity and also its proapoptotic activity in both lens and non-lens cells. ${ }^{5}$ On the other hand, dephosphorylation of $\mathrm{Rb}$ by PP-1 promotes its ability to bind to members of the E2F family and thus negatively regulates apoptosis. ${ }^{59}$ Together, these results point to the conclusion that $\mathrm{PP}-1$ regulates multiple signaling pathways and targets to control cell differentiation and apoptosis.

\section{Experimental Procedures}

Cell culture. The hTERT-transfected HLECs ${ }^{60}$ and ARPE- 19 cells $^{61}$ were grown in Dulbecco's modified Eagle's minimal essential medium (DMEM) (Invitrogen Life Technologies, Carlsbad, CA, USA) containing $10 \%$ fetal bovine serum and 50 Units $/ \mathrm{ml}$ penicillin and streptomycin. All cells were kept at $37^{\circ} \mathrm{C}$ and $5 \% \mathrm{CO}_{2}$ gas phase. HLECs stably transfected with pCl-neo vector, pCl-AKT, pCl-AKT-T450A, pCl-AKTT450D, pCl-PP- $1 \alpha$, pCl-PP- $1 \beta$, pCl-PP- $1 \gamma$, pCl-PP-2A $\alpha$ and pCl-PP-2A $\beta$ were grown in DMEM containing $400 \mu \mathrm{g} / \mathrm{ml} \mathrm{G} 418,10 \%$ fetal bovine serum and 50 Units $/ \mathrm{ml}$ penicillin and streptomycin. Similarly, ARPE-19 cells stably transfected with pCl-neo vector, pCl-AKT, pCl-AKT-T450A and pCl-AKT-T450D were also grown in DMEM containing $400 \mu \mathrm{g} / \mathrm{ml} \mathrm{G} 418,10 \%$ fetal bovine serum and 50 Units $/ \mathrm{ml}$ penicillin and streptomycin.

Preparation of expression constructs. The human Akt1 CDNA was obtained from ATCC (Manassas, VA, USA). The complete coding sequence for Akt1 was excised and inserted into the BamHI/Sall sites of pGEX 4T-1 vector to generate the GST fusion protein using the following primer pairs: $5^{\prime}$-TCCGGATCCATGAGCGACG-TG GCTATTGTGA-3' (forward, F) and 5'-gacgtcgacTCAGGCCGTGCCG-CTGGC-3' (reverse, R). For mutant Akt1-T450A, two primers, 5'-ATGATCACCATCGC ACCACCTGACC- $3^{\prime}$ (F) and 5'-GGTCAGGTGGTGCG-ATGGTGATCAT-3' (R), were used, and for mutant Akt1-T450D, 5'-ATGATCA-CCATCGACCCACC TGACC-3' (F) and 5'-TTGGTCAGGTGGGTCGATG-GTGATC-3' (R) were used. The mutant Akt1 expression constructs, pCl-neo-AKT-T450A and pCl-AKT-T450D were generated using PCR-linked in vitro mutagenesis as described previously. ${ }^{5,6,61}$ Both wild-type and mutant constructs were cloned into $\mathrm{pCl}-$ neo vector at the EcoRI $\left(5^{\prime}\right)$ and Sall $\left(3^{\prime}\right)$ sites.

The human PP- $1 \alpha$, PP- $1 \beta$, PP- $1 \gamma$, PP-2A $\alpha$ and PP-2A $\beta$ catalytic subunits were purchased from ATCC. The coding sequence was excised and inserted into the pCl-neo vector as described previously. ${ }^{6,54}$ The luciferase reporter gene driven by a mini-promoter containing a NF- $\kappa$ B binding site was purchased from Panomics (Fremont, CA, USA).

Stable and transient transfection. pCl-neo, pCl-AKT, pCl-AKT-T450A, pCl-AKT-T450D, pCl-PP- $1 \alpha$, pCl-PP- $1 \beta$, pCl-PP- $1 \gamma$, pCl-PP-2A $\alpha$ and pCl-PP-2A $\beta$ were amplified in $\mathrm{DH}-5 \alpha$ and purified using Qiagen kits (Qiagen, Valencia, CA, USA) or cesium chloride ultracentrifugation as described previously. ${ }^{5,6,60,61}$ After treatment with RNase and extraction by phenol/chloroform, the plasmids were transfected into HLECs, ${ }^{60}$ ARPE- 19 cells $^{61}$ or $\alpha$ TN4-1 cells ${ }^{62}$ using Lipofectamine 2000 (Invitrogen Life Technologies). The transfected cells were either used for experimentation or subjected to G418 $(400 \mu \mathrm{g} / \mathrm{ml})$ selection for 4-6 weeks. In the latter case, the individual clones for the stably transfected cell lines were established and confirmed with RT-PCR and western blot analysis.

Pretreatment by JNK1/2 inhibitor, SP600125. Parental or various silence constructs-transfected or overexpression HLEC clones were grown to $95 \%$ confluence, then pretreated with $1 \mu \mathrm{M} \mathrm{SP} 600125$, JNK1/2 inhibitor $\left(\mathrm{IC}_{50}=40 \mathrm{nM}\right.$ for JNK $1 / 2$ and $90 \mathrm{nM}$ for JNK3) or $0.01 \%$ DMSO (mock) for $0,6,24$ or $48 \mathrm{~h}$, as described previously, ${ }^{30,63}$ followed by treatment with $0-100$ or $200 \mathrm{nM} \mathrm{OA}$ for $3 \mathrm{~h}$ in DMEM (for HLECs) or no further treatment (for detection of basic AKT-Thr-450 phosphorylation level, or for various PP-1 and PP-2A knockdown or overexpression clones). After treatment, cells of different samples were harvested and then the total proteins were isolated for western blot analysis as described below.

Treatment by staurosporin, OA and calyculin A. Parental or various plasmid-transfected HLECs or ARPE-19 cells were grown to $95 \%$ confluence subjected to pretreatment or without pretreatment. A volume of $10 \mathrm{ml}$ of DMEM medium containing $0.01 \%$ DMSO (control) or different concentrations of $O A$, calyculin A or $100 \mathrm{nM}$ staurosporin was then used to replace the culture medium and the treatment was continued for $3 \mathrm{~h}$. After treatment, cells of different samples were harvested and then the total proteins were isolated for western blot analysis as described below.

Silence of the five catalytic subunits of PP-1 and PP-2A. Various human shRNA expression constructs targeting the knockdown of PP- $1 \alpha, \mathrm{PP}-1 \beta$, PP- $1 \gamma$, PP-2A $\alpha$ and PP-2A $\beta$ (Cat no. RHS3979-1022 to RHS3979-1080), as well as the control construct (RHS4078), were purchased from Open Biosystems Inc. Knockdown clones of stable transfection were established under screening with $0.25 \mu \mathrm{g} / \mathrm{ml}$ puromycin for a period of 4 weeks.

Flow cytometry analysis. The apoptosis rate of the pCl-neo-, pCl-AKT-, pCl-AKT-T450A- and pCl-AKT-T450D-transfected stable clones were determined using an Annexin V-FITC Apoptosis Detection kit (BD Biosciences, San Jose, CA, USA) as described previously ${ }^{63}$ Briefly, the treated cells were trypsinized, washed twice with ice-cold Dulbecco's phosphate-buffered saline and incubated at room temperature for $15 \mathrm{~min}$ in the dark with Annexin V-conjugated FITC and propidium iodide in the binding buffer provided. Stained cells were analyzed by flow cytometry using FACSCalibur (BD Biosciences, San Jose, CA, USA).

Protein preparation and western blot analysis. Total proteins from either treated or non-treated cells were extracted as described previously. ${ }^{5,6}$ Total proteins were extracted from various types of cells as specified in the figure legends. The protein concentration was determined as described previously. ${ }^{5,6}$ In all, 50 or $100 \mu \mathrm{g}$ of total proteins were used for each lane of loaded sample. The protein blots were blocked with $5 \%$ milk in TBS buffer overnight at $4{ }^{\circ} \mathrm{C}$ and then incubated for $1 \mathrm{~h}$ or overnight with antibodies against total Akt1, phospho-Akt1 at Thr-308, Thr-450 and Ser-473 (Cell Signaling Inc., Danvers, MA, USA), $\alpha$-crystallin (a kind gift from Dr. Joseph Horvitz, UCLA), PP-1 $\alpha / \beta / \gamma, \mathrm{PP}-2 \mathrm{~A} \alpha / \beta, \beta$-crystallin and N-cadherin (Santa Cruz Biotechnology Inc., Santa Cruz, CA, USA) and $\beta$-actin antibody (Sigma, St. Louis, MO, USA) at a dilution of $1: 200-3000$. The secondary antibody was anti-mouse IgG, anti-rabbit IgG or anti-goat IgG (Habersham Biosciences, Piscataway, NJ, USA) or anti-goat IgG (Santa Cruz Biotechnology Inc.) at a dilution of $1: 1000-3000$. Immunoreactivity was detected as described previously. ${ }^{60-63}$

Immunoprecipitation. Immunoprecipitation of total proteins from normal HLECs and ARPE-19 cells was conducted as described previously. 5,6

In vitro phosphorylation of the purified Akt1 and Akt1-T450A proteins. The fusion proteins of GST-Akt1, GST-Akt1-T450A were prepared as described previously. ${ }^{5,64}$ The fusion protein was further purified by GST column and then cleaved by thrombin protease. Finally, purified Akt1 or Akt1-T450A without GST was used as substrate for the in vitro phosphorylation by JNK1/2. To prepare active JNK1/2 kinases, $10 \mu \mathrm{g}$ of mouse anti-JNK antibody was added to $1 \mathrm{mg}$ of total proteins extracted from HLECs or ARPE-19 cells. After vortexing for $10 \mathrm{~s}$, the mixtures were incubated on ice for $1 \mathrm{~h}$. A volume of $100 \mu \mathrm{l}$ of protein $\mathrm{A} / \mathrm{G}$ plus agarose beads was then added to each protein solution, and the protein solutions were subjected to rotation at $4^{\circ} \mathrm{C}$ overnight. Pellets were collected by centrifugation and washed four times with washing buffer as described previously. ${ }^{5,6,54}$ After washing, the pellets of the precipitated HLECs or ARPE-19 proteins were left in $50 \mu \mathrm{l}$ of $1 \times$ kinase buffer ( $50 \mathrm{mM}$ Tris $7.5,10 \mathrm{mM} \mathrm{MgCl}, 1 \mathrm{mM} \mathrm{EGTA}, 2 \mathrm{mM} \mathrm{DTT}$, $0.01 \%$ Brij35, 0.02\% BSA) and used for labeling the purified Akt1 and Akt1-T450A, which were used as dephosphorylation substrates.

In vitro dephosphorylation assays. The in vitro dephosphorylation assays were conducted as described previously.

Basic FGF induction of differentiation. The pCl-AKT1- $\alpha$ TN4-1, pCl-AKT1-T450A- $\alpha$ TN4-1, pCl-AKT1-T450D- $\alpha$ TN4-1, pCl-AKT1/pCl- $\alpha$ TN4-1 and $\mathrm{pCl}-\mathrm{AKT} 1 / \mathrm{pCl}-\mathrm{PP} 1 \alpha-\alpha \mathrm{TN} 4-1$ cells were starved of serum overnight, followed by $50 \mu \mathrm{g} / \mathrm{ml} \mathrm{bFGF} \mathrm{(Sigma)} \mathrm{treatment} \mathrm{from} 0$ to 5 days without changing the medium.

Analysis of transient gene expression. The Promega dual-luciferase reporter assay system (Promega, Madison, WI, USA) was used in our analysis. For transient luciferase assays, $2.5 \mu \mathrm{g}$ luciferase reporter gene (pNF- $\kappa \mathrm{B}-\mathrm{Luc}$ ) together with $3.5 \mu \mathrm{g} \mathrm{pCl}-\mathrm{AKT1}$, pCl-AKT1-T450A, pCl-AKT1-T450D alone or $3.5 \mu \mathrm{g}$ each plus $1.5 \mu \mathrm{g} \mathrm{pCl}-\mathrm{PP}-1 \alpha$, or $1.5 \mu \mathrm{g} \mathrm{pCl}-\mathrm{PP}-2 \mathrm{~A} \alpha$ and $0.2 \mu \mathrm{g}$ control plasmid Renilla luciferase pRL-SV40-Luc (Cat. no. E2231) were cotransfected into HLECs or ARPE-19 cells using the Lipofectamine 2000 kit from Invitrogen Life Technologies. After $36 \mathrm{~h}$, the transfected cells were harvested for luciferase assays according to the company 
instruction manual. The luciferase activity was determined using the Luminoskan RS microplate reader from Thermo Labsystems Corporation (Waltham, MA, USA).

\section{Confocal immunohistochemistry analysis of the total and active} AKT1 in developing mouse eye. The mouse eye tissues were fixed with $4 \%$ paraformaldehyde in PBS, pH 7.4 and embedded in O.C.T. component (Tissue-Tek, Sakura Finetek USA Inc., Torrance, CA, USA, Cat no. 4583) on dry ice. Sections of 5- $\mu \mathrm{m}$ thickness were cut in a Leica CM1950 Cyrostate (Leica, Allendale, NJ, USA) and adhered to the Superfrost/plus microscope slides (Fisher Scientific, Pittsburgh, PA, USA). The sections were washed three times with PBS. For nonspecific blocking, each section was incubated in $500 \mu \mathrm{l}$ of $5 \%$ normal goat serum (Sigma) in PBS for $1 \mathrm{~h}$ at room temperature and then incubated overnight in $400 \mu \mathrm{l}$ of diluted antibodies $(1: 100)$ in a humidified chamber at $4^{\circ} \mathrm{C}$. The sections were then washed three times ( $5 \mathrm{~min}$ each) with PBS, followed by incubation in $400 \mu \mathrm{l}$ of secondary antibodies linked to FITC or Texas Red (Vector Laboratories, Barlingame, CA, USA) of 1:1000 dilution in blocking solution for $1 \mathrm{~h}$ in the absence of visible light. After incubation, sections were washed six times ( 5 min each) with PBS at room temperature and then observed under a Zeiss confocal fluorescence microscope (Zeiss, Thornwood, NY, USA). For negative controls, the sections were treated in the same manner, except that the primary antibody was replaced by normal serum.

Quantitation and statistical analysis. The western blot gels were analyzed using the UN-SCAN-IT software from Silk Scientific Corporation (Orem, UT, USA). Total pixel data were averaged from three or more different groups of samples of each species after normalization against the background. The total pixels from the target band were divided by the total pixels from the corresponding $\beta$-actin or total Akt1 (the reference band as specified in each figure legend).

In this study, all data presented are derived from at least three experiments. During data analysis, statistical analysis was conducted for all sets of data when necessary The means, S.D. and $P$-value were calculated and included in the figures.

\section{Conflict of interest}

The authors declare no conflict of interest.

Acknowledgements. This study is supported in part by the National Institute of Health Grants 1 R01EY15765 and 1 R01EY18380, the Changjiang Scholar Team Award Funds from Education Ministry of China, the Lotus Scholar Program Funds from Hunan Province Government and the Special Honorary Professorship Funds from Hunan Normal University.

1. Moorhead GBG, Trinkle-Mulcahy L, Ulke-Lemée A. Emerging roles of nuclear protein phosphatases. Nat Rev Mol Cell Biol 2007; 8: 234-244.

2. Yan Q, Mao Y-W, Li DW. Protein serine/threonine phosphatases in the nerve system. In Binder, Hirokawa, Windhorst (eds). Encyclopedia of Neuroscience. Springer: Heidelberg, 2009, pp 3325-3329.

3. Cohen P. The structure and regulation of protein phosphatases. Annu Rev Biochem 1989; 58: 453-508.

4. Mumby MC, Walter G. Protein serine/threonine phosphatases: structure, regulation, and functions in cell growth. Physiol Rev 1993; 73: 673-699.

5. Li DW-C, Liu J-P, Schmid PC, Schelosser R, Feng H, Liu W-B et al. Protein serine/ threonine phosphatase-1 dephosphorylates p53 at Ser-15 and Ser-37 to modulate its transcriptional and apoptotic activities. Oncogene 2006; 25: 3006-3022.

6. Qin J-C, Chen H-J, Yan Q, Deng M, Liu J-P, Doerge S et al. Protein phosphatase-2A is a target of epigallocatechin-3-gallate and regulates p53-Bak apoptotic pathway. Cancer Res 2008; 68: 4150-4162.

7. Dohoney KM, Guillerm C, Whiteford C, Elbi C, Lambert PF, Hager GL et al. Phosphorylation of $\mathrm{p} 53$ at Serine 37 is important for transcriptional activity and regulation in response to DNA damage. Oncogene 2004; 23: 49-57.

8. Scheid MP, Woodgett JR. PKB/AKT: functional insights from genetic models. Nat Rev Mol Cell Biol 2001; 2: 760-768.

9. Datta SR, Brunet A, Greenberg ME. Cellular survival: a play in three Akts. Genes Dev 1999; 13: 2905-2927.

10. Franke TF, Kaplan DR, Cantley LC. PI3K: downstream AKTion blocks apoptosis. Cell 1997; 88: 435-437.

11. Black JD. Protein kinase C-mediated regulation of the cell cycle. Front Biosci 2000; $\mathbf{5}$ D406-D423.

12. Lawlor MA, Alessi DR. PKB/Akt: a key mediator of cell proliferation, survival and insulin responses? J Cell Sci 2001; 114: 2903-2910.

13. Nicholson KM, Anderson NG. The protein kinase B/Akt signalling pathway in human malignancy. Cell Signal 2002; 14: 381-395.
14. Vivanco I, Sawyers $\mathrm{CL}$. The phosphatidylinositol 3-kinase AKT pathway in human cancer. Nat Rev Cancer 2002; 2: 489-501.

15. Shaw J, Kirshenbaum JA. Prime time for JNK-mediated Akt reactivation in hypoxiareoxygenation. Circ Res 2006; 98: 7-9.

16. Shao Z, Bhattacharya K, Hsich E, Park L, Walters B, Germann U et al. c-Jun N-terminal kinases mediate reactivation of Akt and cardiomyocyte survival after hypoxic injury in vitro and in vivo. Circ Res 2006; 98: 111-118.

17. Alessi DR, Andjelkovic M, Caudwell B, Cron P, Morrice N, Cohen $P$ et al. Mechanism of activation of protein kinase B by insulin and IGF-1. EMBO J 1996; 15: 6541-6551.

18. Stephens L, Anderson K, Stokoe D, Erdjument-Bromage H, Painter GF, Holmes AB et al. Protein kinase $B$ kinases that mediate phosphatidylinositol 3,4,5-trisphosphate-dependent activation of protein kinase B. Science 1998; 279: 710-714.

19. Behn-Krappa A, Newton AC. The hydrophobic phosphorylation motif of conventional protein kinase $C$ is regulated by autophosphorylation. Curr Biol 1999; 9: 728-737.

20. Toker A, Newton AC. Akt/protein kinase B is regulated by autophosphorylation at the hypothetical PDK-2 site. J Biol Chem 2000; 275: 8271-8274.

21. Leslie NR, Biondi RM, Alessi DR. Phosphoinositide-regulated kinases and phosphoinositide phosphatases. Chem Rev 2001; 101: 2365-2380.

22. Sarbassov DD, Guertin DA, Ali SM, Sabatini DM. Phosphorylation and regulation of Akt/PKB by the rictor-mTOR complex. Science 2005; 307: 1098-1101.

23. Jacinto E, Facchinetti V, Liu D, Soto N, Wei S, Jung SY et al. SIN1/MIP1 maintains rictor-mTOR complex integrity and regulates Akt phosphorylation and substrate specificity. Cell 2006; 127: 125-137.

24. Maehama T, Dixon JE. The tumor suppressor, PTEN/MMAC1, dephosphorylates the lipid second messenger, phosphatidylinositol 3,4,5-trisphosphate. J Biol Chem 1998; 273: 13375-13378

25. Wishart MJ, Dixon JE. PTEN and myotubularin phosphatases: from 3-phosphoinositide dephosphorylation to disease. Trends Cell Biol 2002; 12: 579-585.

26. Gao T, Furnari F, Newton AC. PHLPP: a phosphatase that directly dephosphorylates Akt, promotes apoptosis, and suppresses tumor growth. Mol Cell 2005; 18: 13-24.

27. Brognard J, Sierecki E, Gao T, Newton AC. PHLPP and a second isoform, PHLPP2, differentially attenuate the amplitude of Akt signaling by regulating distinct Akt isoforms. Mol Cell 2007; 25: 917-931.

28. Andjelkovic M, Jakubowicz T, Cron P, Ming XF, Han JW, Hemmings BA. Activation and phosphorylation of a pleckstrin homology domain containing protein kinase (RAC-PK/PKB) promoted by serum and protein phosphatase inhibitors. Proc Natl Acad Sci USA 1996; 93 : 5699-5704

29. Kuo Y-C, Huang K-Y, Yang C-H, Yang Y-S, Lee W-Y, Chiang C-W. Regulation of phosphorylation of Thr-308 of Akt, cell proliferation, and survival by the B55alpha regulatory subunit targeting of the protein phosphatase $2 \mathrm{~A}$ holoenzyme to Akt. J Biol Chem 2008; 283: 1882-1892.

30. Han Z, Boyle DL, Chang L, Bennett B, Karin M, Yang L et al. C-Jun N-terminal kinase is required for metalloproteinase expression and joint destruction in inflammatory arthritis. $J$ Clin Invest 2001; 108: 73-81.

31. Xing $Y, X u Y, C h e n Y$, Jeffrey $P D$, Chao $Y$, Zheng $L$ et al. Structure of protein phosphatase 2A core enzyme bound to tumor-inducing toxins. Cell 2006; 127: 341-352.

32. Liu JP, Schlosser R, Ma WY, Dong Z, Feng H, Lui L et al. Human alphaA- and alphaBcrystallins prevent UVA-induced apoptosis through regulation of PKCalpha, RAF/MEK/ ERK and AKT signaling pathways. Exp Eye Res 2004; 79: 393-403.

33. Fujio $Y$, Nguyen $T$, Wencker $D$, Kitsis RN, Walsh $K$. Akt promotes survival of cardiomyocytes in vitro and protects against ischemia-reperfusion injury in mouse heart. Circulation 2000; 101: 660-667.

34. Matsui T, Tao J, del Monte F, Lee KH, Li L, Picard MH et al. Akt activation preserves cardiac function and prevents injury after transient cardiac ischemia in vivo. Circulation 2001; 104: 330-335.

35. McAvoy JW, Chamberlain CG. Growth factors in the eye. Prog Growth Factor Res 1990; 2 : 29-43.

36. Lang RA. Which factors stimulate lens fiber cell differentiation in vivo? Invest Ophthalmo Vis Sci 1999; 40: 3075-3078.

37. Govindarajan V, Overbeek PA. Secreted FGFR3, but not FGFR1, inhibits lens fiber differentiation. Development 2001; 128: 1617-1627.

38. Lovicu FJ, McAvoy JW. FGF-induced lens cell proliferation and differentiation is dependent on MAPK (ERK1/2) signalling. Development 2001; 128: 5075-5084.

39. Le AC, Musil LS. A novel role for FGF and extracellular signal-regulated kinase in gap junction-mediated intercellular communication in the lens. J Cell Biol 2001; 154: 197-216.

40. Ochi H, Ogino H, Kageyama Y, Yasuda K. The stability of the lens-specific Maf protein is regulated by fibroblast growth factor (FGF)/ERK signaling in lens fiber differentiation. J Biol Chem 2003; 278: 537-544.

41. Pearson G, Robinson F, Beers Gibson T, Xu BE, Karandikar M, Berman K et al. Mitogen-activated protein (MAP) kinase pathways: regulation and physiological functions. Endocr Rev 2001; 22: 153-183.

42. Chandrasekher G, Sailaja D. Phosphatidylinositol 3-kinase (PI-3K)/Akt but not PI-3K/p70 S6 kinase signaling mediates IGF-1-promoted lens epithelial cell survival. Invest Ophthalmol Vis Sci 2004; 45: 3577-3588.

43. Gotoh N, Ito M, Yamamoto S, Yoshino I, Song N, Wang Y et al. Tyrosine phosphorylation sites on FRS2alpha responsible for Shp2 recruitment are critical for induction of lens and retina. Proc Natl Acad Sci USA 2004; 101: 17144-17149. 
44. James C, Collison DJ, Duncan G. Characterization and functional activity of thrombin receptors in the human lens. Invest Ophthalmol Vis Sci 2005; 46: 925-932.

45. lyengar L, Patkunanathan B, Lynch OT, McAvoy JW, Rasko JE, Lovicu FJ. Aqueous humour- and growth factor-induced lens cell proliferation is dependent on MAPK/ERK1/2 and Akt/PI3-K signalling. Exp Eye Res 2008; 83: 667-678.

46. Jiang $Y$, Luo W, Howe PH. Dab2 stabilizes Axin and attenuates Wnt/beta-catenin signaling by preventing protein phosphatase 1 (PP1)-Axin interactions. Oncogene 2009; 28: 2999-3007.

47. Shi W, Sun C, He B, Xiong W, Shi X, Yao D et al. GADD34-PP1c recruited by Smad7 dephosphorylates TGFbeta type I receptor. J Cell Biol 2004; 164: 291-300.

48. Li HY, Liu H, Wang CH, Zhang JY, Man JH, Gao YF et al. Deactivation of the kinase IKK by CUEDC2 through recruitment of the phosphatase PP1. Nat Immunol 2008; 9: 533-541.

49. Novoa I, Zeng H, Harding HP, Ron D. Feedback inhibition of the unfolded protein response by GADD34-mediated dephosphorylation of elF2alpha. J Cell Biol 2001; 53: 1011-1022.

50. Jousse C, Oyadomari S, Novoa I, Lu P, Zhang Y, Harding HP et al. Inhibition of a constitutive translation initiation factor 2alpha phosphatase, $\mathrm{CReP}$, promotes survival of stressed cells. J Cell Biol 2003; 163: 767-775.

51. Connor JH, Weiser DC, Li S, Hallenbeck JM, Shenolikar S. Growth arrest and DNA damage-inducible protein GADD34 assembles a novel signaling complex containing protein phosphatase 1 and inhibitor 1. Mol Cell Biol 2001; 21: 6841-6850.

52. Lee $Y Y$, Cevallos RC, Jan $E$. An upstream open reading frame regulates translation of GADD34 during cellular stresses that induce elF2alpha phosphorylation. J Biol Chem 2009; 284: 6661-6673.

53. Kim SS, Kim JH, Lee SH, Chung SS, Bang OS, Park D et al. Involvement of protein phosphatase-1-mediated MARCKS translocation in myogenic differentiation of embryonic muscle cells. J Cell Sci 2002; 115 (Pt 12): 2465-2473.
54. Yan Q, Liu W-B, Qin J, Liu J-P, Chen H-G, Huang $X$ et al. Protein phosphatase-1 dephosphorylates Pax-6, a transcription factor controlling brain and eye development. J Biol Chem 2007; 282: 13954-13965.

55. Miyashita T, Krajewski S, Krajewska M, Wang HG, Lin HK, Liebermann DA et al. Tumor suppressor p53 is a regulator of bcl-2 and bax gene expression in vitro and in vivo. Oncogene 1994; 9: 1799-1805.

56. Mihara M, Erster S, Zaika A, Petrenko O, Chittenden T, Pancoska P et al. p53 has a direct apoptogenic role at the mitochondria. Mol Cell 2003; 11: 577-590.

57. Leu JI, Dumont P, Hafey M, Murphy ME, George DL. Mitochondrial p53 activates Bak and causes disruption of a Bak-Mcl1 complex. Nat Cell Biol 2004; 6: 443-450.

58. Bode AM, Dong ZG. Post-translational modification of p53 in tumorigenesis. Nat Rev Cancer 2004; 4: 793-805.

59. Kim TH, Goodman J, Anderson KV, Niswander L. Phactr4 regulates neural tube and optic fissure closure by controlling PP1-, Rb-, and E2F1-regulated cell-cycle progression. Dev Cell 2007; 13: 87-102.

60. Xiang H, Wang J, Mao Y, Liu M, Reddy VN, Li DW. Human telomerase accelerates growth of lens epithelial cells through regulation of the genes mediating RB/E2F pathway. Oncogene 2002; 21: 3784-3791.

61. Mao YW, Liu JP, Xiang H, Li DW. Human alphaA- and alphaB-crystallins bind to Bax and $\mathrm{Bcl}-\mathrm{X}(\mathrm{S})$ to sequester their translocation during staurosporine-induced apoptosis. Cell Death Differ 2004; 11: 512-526.

62. Chen H-G, Han W-J, Deng M, Qin J-C, Yuan D, Liu J-P et al. Transcriptional regulation of PP2A-A $\alpha$ is mediated by multiple factors including AP-2 $\alpha$, CREB, ETS, and SP-1. PLOS ONE 2009; 4: e7019.

63. Li DW-C, Liu J-P, Mao YW, Xiang H, Wang J, Ma W-Y. et al. Calcium-activated RAF/MEK ERK pathway mediates p53-dependent apoptosis and is abrogated by $\alpha \mathrm{B}$-crystallin through inhibition of Ras activation. Mol Biol Cell 2005; 16: 4437-4453.

\section{Supplementary Information accompanies the paper on Cell Death and Differentiation website (http://www.nature.com/cdd)}

